Cite this paper as: Davor Rašić, Samuel Rodman Oprešnik, Tine Seljak, Rok Vihar, Urban Žvar Baškovič, Tomaž Wechtersbach, Tomaž Katrašnik, RDE-based assessment of a factory bi-fuel CNG/gasoline light-duty vehicle, Atmospheric Environment, Volume 167, 2017, Pages 523-541, ISSN 1352-2310, https://doi.org/10.1016/j.atmosenv.2017.08.055.

\title{
RDE-based assessment of a factory bi-fuel CNG/gasoline light- duty vehicle
}

\author{
*Davor Rašić, Samuel Rodman Oprešnik, Tine Seljak, Rok Vihar, Urban Žvar \\ Baškovič, Tomaž Wechtersbach, Tomaž Katrašnik
}

Faculty of Mechanical Engineering, University of Ljubljana, Aškerčeva 6, SI-1000 Ljubljana, Slovenia

*corresponding author

\begin{abstract}
On-road exhaust emissions of a Euro 5 factory bi-fuel CNG/gasoline light-duty vehicle equipped with the TWC were assessed considering the Real Driving Emissions (RDE) guidelines. The vehicle was equipped with a Portable Emission Measurement System (PEMS) that enabled the measurement of $\mathrm{THC}, \mathrm{CO}, \mathrm{NO}_{\mathrm{x}}, \mathrm{CO}_{2}$, and $\mathrm{CH}_{4}$. With respect to the characteristics of the vehicle, the appropriate Worldwide Harmonized Light-Duty Vehicle Test Cycles (WLTC) were selected and based on the requirements of the RDE legislation a suitable route was conceived. In addition to the moderate RDE-based route, an extended RDE-based route was also determined. The vehicle was driven along each defined route twice, once with each individual fuel option and with a fully warm vehicle.

RDE routes feature a multitude of new driving patterns that are significantly different to those encountered in the NEDC. However, as these driving patterns can greatly influence the cumulative emissions an insight in to local time trace phenomena is crucial to understand, reason and to possibly reduce the cumulative emissions. Original contributions of this paper comprise analyses of the RDE-LDV local time resolved driving emissions phenomena of a CNG-powered vehicle that are benchmarked against the ones measured under the use of gasoline in the same vehicle and under similar operating conditions to reason emission trends through driving patterns and powertrain parameters and exposing the strong cold-start independent interference of $\mathrm{CO}$ and $\mathrm{N}_{2} \mathrm{O}$ infrared absorption bands in the non-dispersive infrared (NDIR) analyzer. The paper provides experimental evidence on this interference, which significantly influences on the readings of $\mathrm{CO}$ emissions. The paper further provides hypotheses why $\mathrm{CO}$ and $\mathrm{N}_{2} \mathrm{O}$ interference is more pronounced when using CNG in LDVs and supports these hypotheses by PEMS tests.

The study reveals that the vehicle's $\mathrm{NO}_{\mathrm{x}}$ real-world emission values of both conceived RDE-based routes when using both fuels are within Euro 5 and type-approval limits. Additionally, the THC and the NMHC emissions of both RDE-based routes using both fuels are within the Euro 5 limits indicating reasonable $\mathrm{CH}_{4}$ emissions. Notable increases above the type-approval and Euro 5 limits appeared in the $\mathrm{CO}$ emissions profile when using gasoline, while the $\mathrm{CO}_{2}$ emissions profile expectedly also exceeded the type-approval specifications.
\end{abstract}

\section{Highlights}

- A factory bi-fuel CNG/gasoline LDV was assessed considering the proposed RDE guidelines

- CNG RDE-LDV results are benchmarked against the ones of the gasoline fuel 
Cite this paper as: Davor Rašić, Samuel Rodman Oprešnik, Tine Seljak, Rok Vihar, Urban Žvar Baškovič, Tomaž Wechtersbach, Tomaž Katrašnik, RDE-based assessment of a factory bi-fuel CNG/gasoline light-duty vehicle, Atmospheric Environment, Volume 167, 2017, Pages 523-541, ISSN 1352-2310,

https://doi.org/10.1016/j.atmosenv.2017.08.055.

- In addition to $\mathrm{THC}, \mathrm{CO}, \mathrm{NO}_{x}$ and $\mathrm{CO}_{2}, \mathrm{CH}_{4}$ was also measured during the $\mathrm{RDE}$ test

- Strong interference of $\mathrm{CO}$ and $\mathrm{N}_{2} \mathrm{O}$, which affects the $\mathrm{CO}$ readings of the NDIR is exposed

- Hypotheses on $\mathrm{CO}$ and $\mathrm{N}_{2} \mathrm{O}$ interference for $\mathrm{CNG}$ are proposed and supported by PEMS results

Key words: RDE, PEMS, light-duty vehicle, $\mathrm{CNG}$, gasoline

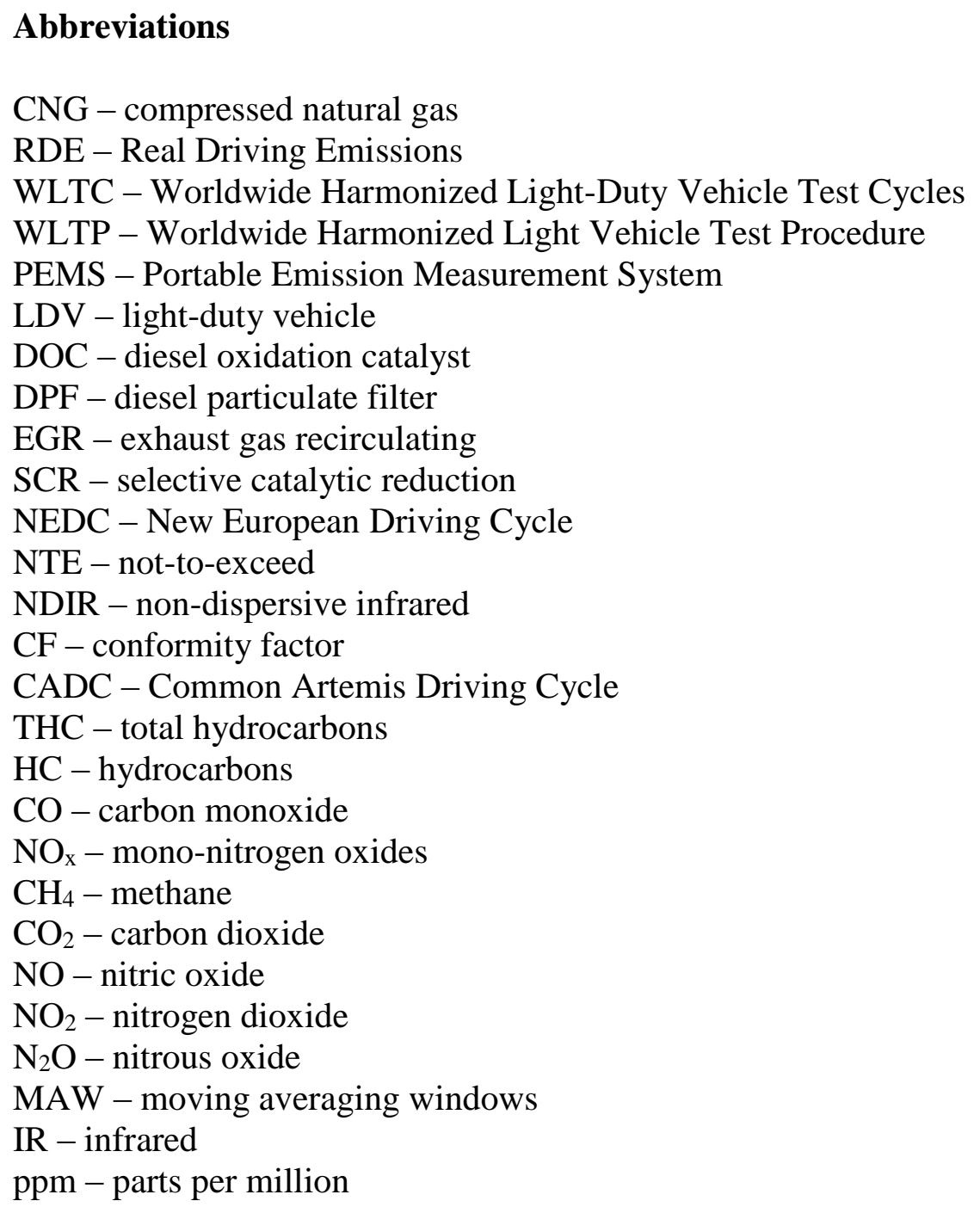

\section{Introduction}

Environmental protection is one of the key challenges of modern society and reduction of exhaust emissions from the transport section is one of the crucial pillars to achieve this goal. This aim is clearly reflected in the reduction of emission limits in emission legislations around the globe. However, during the last decades, it also became evident that real-world exhaust emission of the vehicle fleet did not follow the reductions imposed by the emission legislation [11, 13, 14, 18 and 19]. Similar can also be concluded for the fuel consumption [11, 13, 14].

Future emission regulation in the field of light-duty vehicles (LDV) aims to address these challenges relying on the newly established Real Driving Emissions (RDE) legislation [8, 27]. 
Cite this paper as: Davor Rašić, Samuel Rodman Oprešnik, Tine Seljak, Rok Vihar, Urban Žvar Baškovič, Tomaž Wechtersbach, Tomaž Katrašnik, RDE-based assessment of a factory bi-fuel CNG/gasoline light-duty vehicle, Atmospheric Environment, Volume 167, 2017, Pages 523-541, ISSN 1352-2310, https://doi.org/10.1016/j.atmosenv.2017.08.055.

Additionally, within the framework of the Worldwide Harmonized Light Vehicles Test Procedure (WLTP), a Worldwide Harmonized Light-duty driving Test Cycle (WLTC) is planned to be introduced in 2017 [12, 16, 20, 21]. In EU, it is planned to replace the existing New European Driving Cycle (NEDC) that is in general characterized by lower average and peak engine power requirements and is currently still used for assessing compliance with Euro emissions standards. While the RDE-LDV emission legislation is thoroughly elaborated in the $\mathrm{EU}[8,27]$ and is the main focus of this paper, it must be mentioned that the US will be adopting a new standard named US-EPA Tier 3, which will tighten the emission limits on the established cycles FTP-75, HWFET and the supplemental cycles US06 and SC03. To comply with the new US emission standards, manufacturers will thus have to follow test procedures specified in 40 Code of Federal Regulations (CFR) part 1066 [23, 24].

The introduction of on-road measurements has already proven to be successful for heavyduty vehicles $[29,30,31,32]$. The invoking of the Euro VI emission standard for heavy-duty vehicles resulted in severe $\mathrm{NO}_{\mathrm{x}}$ and $\mathrm{PM}$ reductions during real-world driving [29, 30, 31, 32]. This is primarily due to the application of diesel oxidation catalysts (DOC), diesel particulate filters (DPF), exhaust gas recirculation (EGR), selective catalytic reduction (SCR) and ammonia-selective catalytic reduction $\left(\mathrm{NH}_{3}-\mathrm{SCR}\right)$ of the exhaust gasses [25, 30, 31, 32].

Although the RDE-LDV test procedure $[8,27]$ is yet not adopted by the EU Parliament, the documentation is elaborated in detail, and thus allows execution and validation of the tests. The documentation anticipates that, in addition to new vehicles, the test procedure will be conducted on vehicles with mileage up to $100.000 \mathrm{~km}$ [9]. For the purpose of testing, the use of portable emission measurement systems (PEMS) and not-to-exceed (NTE) regulatory concepts have been suggested $[8,27]$. RDE tests should reproduce a representative range of driving patterns and styles to ensure that the generated emissions correspond to those typically emitted during real driving. The NTE emission limits represent the legal emission limits plus a margin called the conformity factor $(\mathrm{CF})[8,27]$.

Only a limited amount of studies have addressed the relatively contemporary subject of measuring real-world driving emissions. In [1], two Euro 6 diesel vehicles were evaluated both on-road and over various dyno test cycles. It was stated that real-world driving routes influenced the pollutant emissions [1]. It was further reported that the $\mathrm{CO}$ and $\mathrm{HC}$ emissions were well within Euro 6 limits for all analyzed routes but $\mathrm{NO}_{\mathrm{x}}$ emissions were substantially above the NTE, considering the CF of 1.5 [1]. In [2], the concern of exceedingly high real-world driving emissions was addressed by analyzing gaseous emissions of one Euro 6 and six Euro 4-5 diesel vehicles with PEMS. Although considerably lower $\mathrm{NO}_{\mathrm{x}}$ emissions of the Euro 6 vehicle compared to the Euro 4-5 vehicles were observed, it was still discovered that all tested vehicles substantially exceeded their respective $\mathrm{NO}_{\mathrm{x}}$ emission limits [2]. In [3], the Association for Emissions Control by Catalyst (AECC) published their findings on a series of conducted tests on a Euro 5 gasoline vehicle and on a Euro 6 diesel vehicle. Substantial differences for some pollutants between RDE emissions measured with PEMS equipment compared to the dynamometer tests using NEDC and CADC cycles were reported in this analysis. The study revealed that both vehicles emitted significantly higher values of $\mathrm{NO}_{\mathrm{x}}$ on the RDE route than on the dynamometer cycles, which also exceed their respective Euro limit. Moreover, it was claimed that the high $\mathrm{NO}_{\mathrm{x}}$ emissions particularly occur under high velocities and loads [3], which is expected. Nevertheless, RDE emissions of $\mathrm{CO}$ and $\mathrm{HC}$ were below the respective Euro limit values for both vehicles. The International Council of Clean Transportation (ICCT) published an analysis of on-road emissions data from several Euro 6 passenger vehicles in [4]. It was reported that the $\mathrm{CO}$ and THC emissions were well below the Euro 6 emission limits, while the $\mathrm{NO}_{\mathrm{x}}$ real-world emissions exceeded the regulatory emission limit by more than six times. A similar conclusion was made in [54], where the German Ministry of Transport 
Cite this paper as: Davor Rašić, Samuel Rodman Oprešnik, Tine Seljak, Rok Vihar, Urban Žvar Baškovič, Tomaž Wechtersbach, Tomaž Katrašnik, RDE-based assessment of a factory bi-fuel CNG/gasoline light-duty vehicle, Atmospheric Environment, Volume 167, 2017, Pages 523-541, ISSN 1352-2310, https://doi.org/10.1016/j.atmosenv.2017.08.055.

commissioned a series of laboratory and on-road vehicle tests of 53 different vehicle models in order to determine the use of illegal defeat devices by major vehicle manufacturers. In [5], the Joint Research Centre analyzed on-road emissions of 12 light-duty diesel and gasoline vehicles that comply with Euro 3-5 emission limits. It was disclosed that the $\mathrm{NO}_{\mathrm{x}}$ emissions of diesel vehicles, including Euro 5 vehicles, notably exceeded the respective Euro 3-5 emission limits [5]. On the other hand, $\mathrm{NO}_{\mathrm{x}}$ emissions of gasoline vehicles as well as $\mathrm{CO}$ and $\mathrm{THC}$ emissions of both diesel and gasoline vehicles generally remain within Euro 3-5 emission limits.

In [15], a bi-fuel Euro 5 (CNG/gasoline) vehicle was tested over the NEDC on a chassis dynamometer. It was noted that the $\mathrm{CO}_{2}$ emissions were 24-25\% lower when running on CNG compared to the gasoline use [15], which is in line with H/C ratio of both fuels based on the energy content. In [15], it was also stated that emission testing of CNG under real-world conditions, which is not presented in [15], is necessary in order to have a complete picture of the environmental performance of CNG usage in Euro 5/6 vehicles. In [22], steady-state tests on a chassis dynamometer were performed with a passenger car powered by a retrofitted spark ignition engine using gasoline and $\mathrm{CNG}$. The paper reports that the $\mathrm{CO}$ emissions when using CNG were significantly lower compared to the ones when using gasoline [22]. In addition, it was reported that the vehicle emitted more $\mathrm{NO}_{\mathrm{x}}$ when using $\mathrm{CNG}$ than when using gasoline. It was concluded that higher $\mathrm{NO}_{\mathrm{x}}$ emissions are the main concern when using $\mathrm{CNG}$ [22]. Based on the literature review it can thus be concluded that there is a need for analyses of the RDELDV emissions of a CNG-powered vehicle, which is the subject of the present paper, as such type of analyses were, to the best of author's knowledge, not yet published. This paper presents analyses of the time resolved on-road real driving emissions phenomena of a CNG-powered vehicle, benchmarking them with those measured for gasoline in the same vehicle under similar operating conditions and reasoning of the emission trends through driving conditions and powertrain parameters. The latter is of particular importance as this topic is not deeply explored for RDE-based cycles and thus interrelation of driving conditions and powertrain parameters to the time resolved emission traces provide insightful information that can contribute to reducing cumulative emissions. To additionally strengthen the paper, an indicative comparison and assessment of real-world on-road emissions of a Euro 5 bi-fuel CNG/gasoline light commercial vehicle equipped with the TWC to the Euro 5 regulatory limit being the type-approval limit for the tested vehicle is presented. The deviation of realistic on-road emission footprint along RDEbased routes from the type-approval limit serves an important information of the vehicle's performance over the plausible vehicle operation range. This was recently mostly done for diesel and gasoline vehicles but rarely for $\mathrm{CNG}$ vehicles.

It is also important to note that the Euro 5 introduced stricter methane limits for positive ignition vehicles, specifically with enforcing an NMHC (non-methane hydrocarbons) limit which complements the THC (total hydrocarbons) limit. To address this concern, this paper reports $\mathrm{CH}_{4}$ emissions measured in real-world driving. This was possible with the application of a new generation PEMS that is, besides measuring $\mathrm{CO}, \mathrm{CO}_{2}, \mathrm{NO}, \mathrm{NO}_{2}$ and THC emissions, also capable of measuring $\mathrm{CH}_{4}$ emissions. This further strengthens this study, as, to the best of our knowledge, $\mathrm{CH}_{4}$ emissions were not yet measured during the real-world driving.

Moreover, the paper additionally exposes the strong interference of $\mathrm{CO}$ and $\mathrm{N}_{2} \mathrm{O}$ infrared absorption bands, which can significantly affect the $\mathrm{CO}$ readings from the non-dispersive infrared (NDIR) sensor being the most widespread sensor in a PEMS. This hypothesis was made by analyses of time traces of the CNG fuel vehicle and it was proven by an independent experiment with a similar commercially available analyzer of another manufacturer that clearly exposed correlation between $\mathrm{N}_{2} \mathrm{O}$ presence in the gas fed to the NDIR analyzer and the $\mathrm{CO}$ readings. Since the $\mathrm{CO}$ measurement error appears only when the vehicle was using $\mathrm{CNG}$, the paper also suggests a plausible route of $\mathrm{N}_{2} \mathrm{O}$ formation considering engine-out emission and 
Cite this paper as: Davor Rašić, Samuel Rodman Oprešnik, Tine Seljak, Rok Vihar, Urban Žvar Baškovič, Tomaž Wechtersbach, Tomaž Katrašnik, RDE-based assessment of a factory bi-fuel CNG/gasoline light-duty vehicle, Atmospheric Environment, Volume 167, 2017, Pages 523-541, ISSN 1352-2310, https://doi.org/10.1016/j.atmosenv.2017.08.055.

chemical kinetics in the TWC specific to the use of CNG. Consequently, the presence of $\mathrm{N}_{2} \mathrm{O}$ can significantly influence the test cycle cumulative $\mathrm{CO}$ emission readings. Due to the clear physical background of these phenomena, it can be considered that this is a general challenge rather than an equipment specific effect.

The RDE regulation opens a huge variation space in terms of driving patterns that are significantly different to the ones encountered in the NEDC. As one of the main aims of the paper is focused on analyzing these, previously unexplored, driving patterns and to provide a cause and effect explanation between driving patterns, powertrain parameters and tailpipe emissions, we purposely kept the number of additional variations to a minimum. Therefore, considering complex TWC related phenomena during the catalyst light-off phase, cold starts were intentionally omitted to ensure clarity of analyses, whereas other RDE trip boundary conditions were respected.

To the best of the author's knowledge, this paper comprises the following original contributions: a) analyses of the RDE-LDV emissions of a CNG-powered vehicle; b) benchmarking of the CNG RDE-LDV results with the ones measured for gasoline in the same vehicle and under similar operating conditions; c) measurements of on-road RDE-based route $\mathrm{CH}_{4}$ emissions using a PEMS; d) exposing the strong interference of $\mathrm{CO}$ and $\mathrm{N}_{2} \mathrm{O}$ infrared absorption bands, which can significantly influence the $\mathrm{CO}$ readings from the non-dispersive infrared sensor (NDIR); and e) revealing the hypotheses why $\mathrm{CO}$ and $\mathrm{N}_{2} \mathrm{O}$ interference is more pronounced when using CNG in LDVs.

\section{Experiment}

\subsection{Test vehicle and PEMS instrumentation}

Table 1 summarizes key characteristics of the vehicle. Test vehicles' payload comprised of the driver and a PEMS operator who also served as a witness to the test and the test equipment including the power supply devices, summing up to $1996 \mathrm{~kg}$.

Table 1. Test vehicle's characteristics

\begin{tabular}{|l|l|}
\hline Engine capacity $\left[\mathrm{cm}^{3}\right]$ & 1984 \\
\hline Power output & $80 \mathrm{~kW} @ 5400 \mathrm{RPM}$ \\
\hline Compression ratio & $13.5: 1$ \\
\hline Emission standard & Euro 5 \\
\hline Unladen weight $[\mathrm{kg}]$ & 1580 \\
\hline Transmission & Manual \\
\hline Certification CO emissions using CNG[g/km] & 0.3768 \\
\hline Certification $\mathrm{HC}^{3}$ emissions using CNG [g/km] & 0.0294 \\
\hline Certification $\mathrm{NO}_{\mathrm{x}}$ emissions using CNG $[\mathrm{g} / \mathrm{km}]$ & 0.0168 \\
\hline Certification $\mathrm{CO}_{2}$ emissions using CNG $[\mathrm{g} / \mathrm{km}]$ & 156 \\
\hline Odometer at start of tests $[\mathrm{km}]$ & 11202 \\
\hline CNG fuel capacity $[\mathrm{kg}]$ & 26 \\
\hline Gasoline fuel capacity [liters] & 13 \\
\hline
\end{tabular}

A Portable Emissions Measurement System (PEMS) was used to measure emissions during on-road driving over pre-selected routes. The system comprised of an AVL M.O.V.E. PEMS equipment coupled with an exhaust flow meter (EFM). The PEMS enabled the measurement of THC, $\mathrm{CO}, \mathrm{NO}_{\mathrm{x}}, \mathrm{CO}_{2}$, and $\mathrm{CH}_{4}$. An additional feature of the used PEMS is that analyzers of all the aforementioned emissions are combined within one device. 
Cite this paper as: Davor Rašić, Samuel Rodman Oprešnik, Tine Seljak, Rok Vihar, Urban Žvar Baškovič, Tomaž Wechtersbach, Tomaž Katrašnik, RDE-based assessment of a factory bi-fuel CNG/gasoline light-duty vehicle, Atmospheric Environment, Volume 167, 2017, Pages 523-541, ISSN 1352-2310,

https://doi.org/10.1016/j.atmosenv.2017.08.055.

The PEMS analyzer and other main components were installed in the cabin of the vehicle, while the EFM, GPS antenna, and the weather station were installed outside of the vehicle. The EFM was attached to the vehicle's tailpipe and its sensors placed according to the test procedure's specifications. The exhaust mass flow was determined based on a precisely measured differential and absolute pressure, on the exhaust temperature measured with a Ktype thermocouple and with a calibration based equation. Along with the aforementioned parameters, the OBD information was also logged. All gaseous emissions and vehicle performance parameters were sampled at a frequency of $1 \mathrm{~Hz}$.

The gasoline used during the measuring campaign was an EN228 standard 95-octane gasoline fuel. The composition of CNG used during the measuring campaign is given in Table 2. The CNG composition presented in Table 2 indicates that the used CNG consisted mostly of methane $\left(\mathrm{CH}_{4}\right)$. The test sequence of the measuring campaign is presented in Table 3.

Table 2. CNG composition during the measuring campaign

\begin{tabular}{|l|l|}
\hline Component & Average value [mol \%] \\
\hline Methane & 96.170 \\
\hline Butane & 2.307 \\
\hline Propane & 0.519 \\
\hline i-Butane & 0.088 \\
\hline n-Butane & 0.084 \\
\hline neo-Pentane & 0.000 \\
\hline i-Pentane & 0.018 \\
\hline n-Pentane & 0.011 \\
\hline Hexane+ & 0.015 \\
\hline Nitrogen & 0.583 \\
\hline Carbon dioxide & 0.206 \\
\hline
\end{tabular}

Table 3. Measuring campaign test sequence

\begin{tabular}{|l|l|}
\hline Day [/] & Driven route, fuel [/] \\
\hline Day 1 & WLTP, CNG \\
\hline Day 2 & RDE Moderate route, gasoline \\
\hline Day 2 & RDE Moderate route, CNG \\
\hline Day 3 & RDE Extended route, gasoline \\
\hline Day 3 & RDE Extended route, CNG \\
\hline Day 4 & Other routes, CNG \\
\hline
\end{tabular}

\subsection{WLTP}

According to the Annexes laid down in the Global Technical Regulation no. 15 (GTR.15) [7], several conditions of executing the WLTP must be met. The first step in the WLTP is to execute the WLTC considering the category of the testing vehicle. As indicated in the Introduction, the cold start phase was conscientiously neglected. According to the test procedure of Annex 1 [7], the ratio of the unladen mass of the vehicle to its power and vehicle's maximum velocity suggests that the vehicle resides in the WLTP Class 3 category. The maximum velocity of the test vehicle exceeds $120 \mathrm{~km} / \mathrm{h}$, therefore, the vehicle settles in WLTP Class 3b. A complete WLTC cycle for a Class $3 b$ vehicle consists of a low phase (Low 3 ), 
Cite this paper as: Davor Rašić, Samuel Rodman Oprešnik, Tine Seljak, Rok Vihar, Urban Žvar Baškovič, Tomaž Wechtersbach, Tomaž Katrašnik, RDE-based assessment of a factory bi-fuel CNG/gasoline light-duty vehicle, Atmospheric Environment, Volume 167, 2017, Pages 523-541, ISSN 1352-2310, https://doi.org/10.1016/j.atmosenv.2017.08.055.

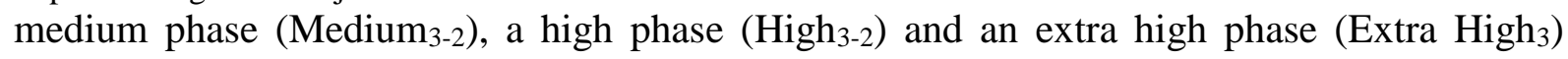
velocity as presented in Fig. 1.

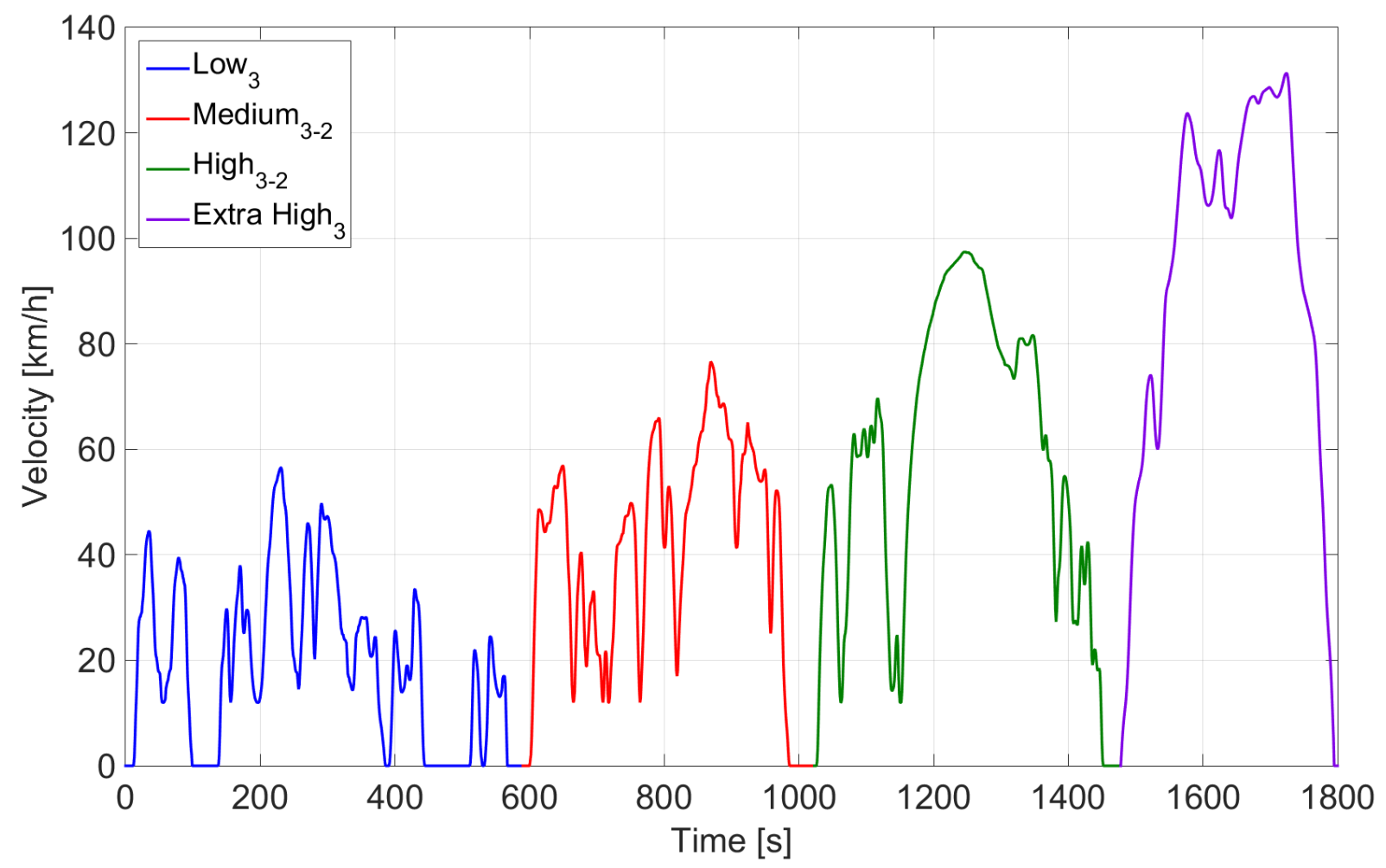

Fig. 1. The WLTC velocity trace for a Class 3b vehicle [7]

In addition to the RDE-based routes, WLTC cycles were also driven on-road in the presented analysis. The WLTC was driven on-road with CNG fuel only. The measuring campaign was performed at night on a straight road with the altitude difference between the start and the end point being roughly $3 \mathrm{~m}$. For the purpose of this campaign, the road was closed, therefore, no traffic was present. The average mean squared error between the legislative vehicle velocity and the on-road driven vehicle velocity was $2.8 \%$. The authors of this study find this error to be low enough to produce a plausible basis for comparative analyses, as the main goal of this study is to present and compare fuel and driving condition specific phenomena. Considering the results published in [17] where the vehicle with an almost identical engine was driven over the NEDC with CNG, gasoline, and LPG fuels a fair estimate of gasoline WLTC $\mathrm{CO}_{2}$ emissions can be made from the CNG WLTC $\mathrm{CO}_{2}$ emission profile given in section 3.1 by considering $\mathrm{H} / \mathrm{C}$ ratio of both fuels based on the energy content.

\subsection{RDE}

The RDE test program was designed considering the $1^{\text {st }}$ package of the RDE-LDV legislation published in March 2016 [8] and the $2^{\text {nd }}$ package of the RDE-LDV legislation published in April 2016 [27]. A general overview of the RDE and WLTP background is given in Appendix A. The RDE performance should reflect the vehicle emissions on the road, operated over its normal driving patterns, conditions, and payloads [8]. In order to evaluate the RDE emissions over the entire plausible vehicle operation range, two RDE-based test routes were developed; one considering the RDE moderate conditions (hereinafter referred to as RDE Moderate route) and the other considering the RDE extended conditions (hereinafter referred to as RDE Extended route). As indicated in the Introduction, given that the cold start condition 
Cite this paper as: Davor Rašić, Samuel Rodman Oprešnik, Tine Seljak, Rok Vihar, Urban Žvar Baškovič, Tomaž Wechtersbach, Tomaž Katrašnik, RDE-based assessment of a factory bi-fuel CNG/gasoline light-duty vehicle, Atmospheric Environment, Volume 167, 2017, Pages 523-541, ISSN 1352-2310, https://doi.org/10.1016/j.atmosenv.2017.08.055.

was not considered when driving the designed routes, the terminology "RDE-based" is used for the analyzed cycles, as the rest of the RDE trip boundary conditions were respected. Therefore, a significant effort was put in maintaining a warm TWC in order to rule out any effect of cold start, which is known to significantly influence the TWC conversion efficiency. Fig. 2 presents the on-road visualization of both driven routes.

The main objective of the RDE Moderate route is to represent a conventional RDE test that is planned to be performed by the appropriate technical services [29] with the invoking of the Euro 6/d standard while the main objective of the RDE Extended route is to test the vehicle's emission footprint on a more power-demanding route. The conditions become extended when at least one of the ambient (temperature or altitude) boundary condition is extended [8]. The legislation states that the maximum altitude above sea level for a moderate route is $700 \mathrm{~m}$ while the maximum altitude above sea level for an extended route is $1300 \mathrm{~m}$ [8]. RDE Extended route was developed in a manner that the maximum altitude above the sea level condition is extended, therefore it must reside between $700 \mathrm{~m}$ and $1300 \mathrm{~m}$ [8], which can be seen from the data in Table 4 presenting the specifications of RDE Moderate and RDE Extended route using both fuel options compared to the RDE trip boundary conditions. The data comparison in Table 4 also reveals that all of the main RDE legislation specific trip boundary conditions were respected throughout the measuring campaign. The test vehicle was driven twice over both developed routes, once with gasoline fuel and once with $\mathrm{CNG}$.

The verification procedure was done considering the EMROAD (also known as the Moving Averaging Windows) method laid down in Appendix 5 of the $1^{\text {st }}$ package of the RDE legislation $[8]$.

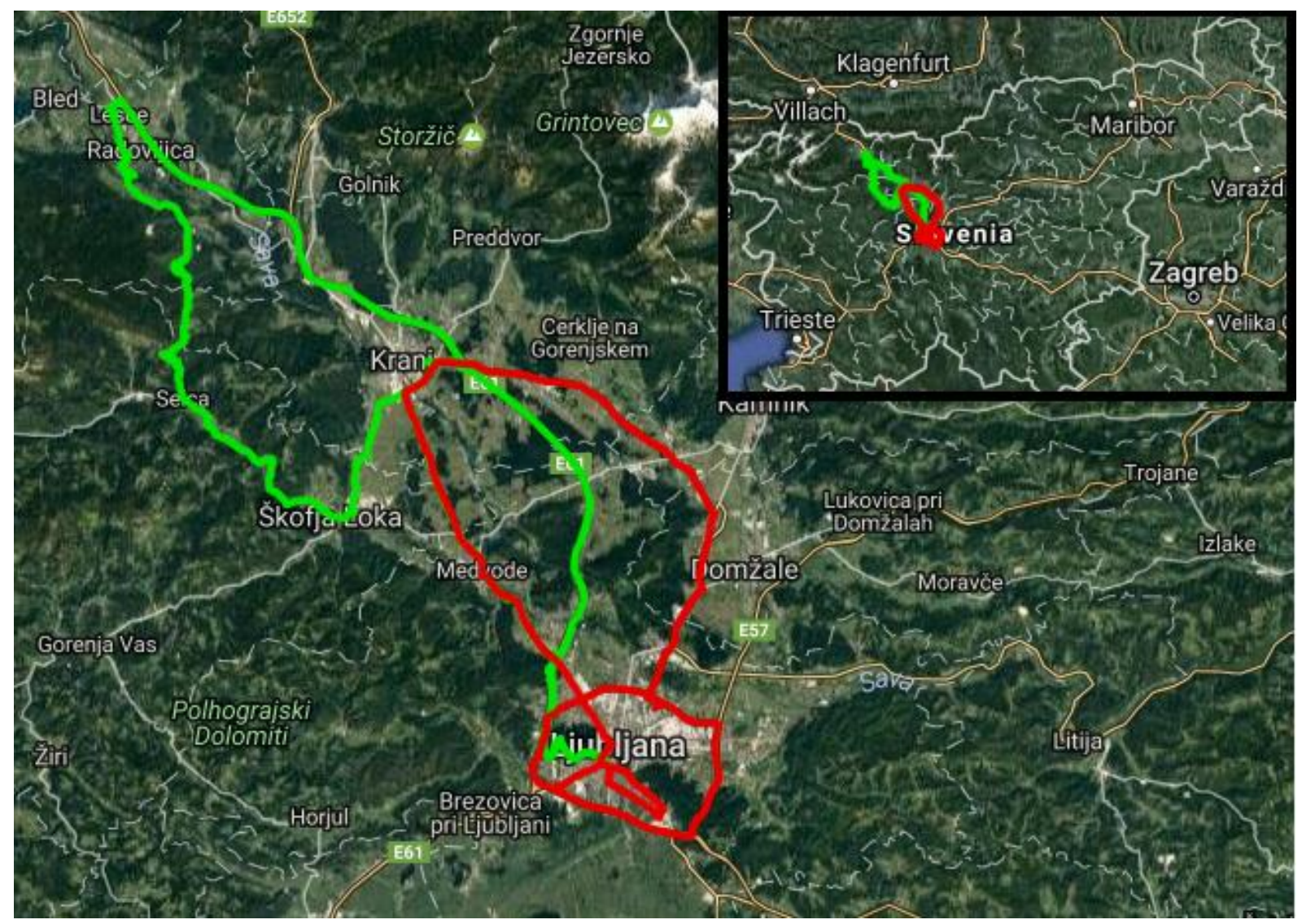

Fig. 2. RDE-based routes: red line - RDE Moderate route, green line - RDE Extended route 
Cite this paper as: Davor Rašić, Samuel Rodman Oprešnik, Tine Seljak, Rok Vihar, Urban Žvar Baškovič, Tomaž Wechtersbach, Tomaž Katrašnik, RDE-based assessment of a factory bi-fuel CNG/gasoline light-duty vehicle, Atmospheric Environment, Volume 167, 2017, Pages 523-541, ISSN 1352-2310, https://doi.org/10.1016/j.atmosenv.2017.08.055.

Table 4. Specifications of RDE Moderate and RDE Extended route using both fuel options compared to the main RDE legislation trip boundary conditions

\begin{tabular}{|l|l|l|l|l|l|}
\hline & RDE Moderate route & \multicolumn{2}{l|}{ RDE Extended route } & $\begin{array}{l}\text { Legislation } \\
\text { boundary } \\
\text { conditions }\end{array}$ \\
\hline & Gasoline & CNG & Gasoline & CNG & \\
\hline Trip duration [min] & 107 & 108 & 102 & 95 & $90-120$ \\
\hline Trip distance [km] & 98.51 & 98.62 & 90.33 & 90.26 & $>48$ \\
\hline $\begin{array}{l}\text { Urban route share } \\
\text { distance [km] }\end{array}$ & 42.9 & 41.04 & 45.38 & 43.6 & $>16$ \\
\hline $\begin{array}{l}\text { Rural route share } \\
\text { distance [km] }\end{array}$ & 32.92 & 32.81 & 20.82 & 22.38 & $>16$ \\
\hline $\begin{array}{l}\text { Highway route share } \\
\text { distance [km] }\end{array}$ & 22.69 & 24.77 & 24.13 & 24.28 & $>16$ \\
\hline $\begin{array}{l}\text { Urban route share trip } \\
\text { average speed [km/h] }\end{array}$ & 39 & 37 & 37 & 40 & $15-40$ \\
\hline $\begin{array}{l}\text { Rural route share trip } \\
\text { average speed [km/h] }\end{array}$ & 71 & 71 & 72 & 72 & $60-90$ \\
\hline $\begin{array}{l}\text { Highway route share } \\
\text { average speed [km/h] }\end{array}$ & 109 & 111 & 120 & 122 & $100-145$ \\
\hline $\begin{array}{l}\text { Cumulative positive } \\
\text { altitude gain [m] }\end{array}$ & 400 & 400 & 915 & 915 & $<1200$ \\
\hline $\begin{array}{l}\text { Maximum trip altitude } \\
\text { [m] }\end{array}$ & 404 & 404 & 860 & 860 & $\begin{array}{l}\text { Moderate < 700 } \\
\text { Extended < 1300 }\end{array}$ \\
\hline Altitude difference [m] & 8 & 8 & 82 & 82 & $<100$ \\
\hline
\end{tabular}

\section{Results}

Emission results analysis of the WLTC test, the RDE Moderate route, and the RDE Extended route is presented in this section.

First, cumulative emissions of the complete data set for each route using both fuels are presented. This data is then compared to the corresponding Euro 5 emission limits and typeapproval limits in an attempt to initially estimate the vehicles' emission footprint. This indicative comparison against the regulatory limit serves as a good indicator to assess the vehicle's on-road emission footprint along an RDE-based route, which is much more powerdemanding than the NEDC and symbolizes a plausible real-life driving route.

Secondly, as this paper is focused on the EMROAD method of RDE verification, which is based on moving averaging windows (MAW), an analysis that covers the results of windowed mass emissions of $\mathrm{CO}, \mathrm{THC}, \mathrm{NO}_{\mathrm{x}}$ and $\mathrm{CO}_{2}$ is presented. Such an analysis is helpful in terms of a comprehensive analysis of the gathered emissions data. Cumulative emissions of THC, CO, and $\mathrm{NO}_{\mathrm{x}}$ over each window are compared to the corresponding Euro 5 emission limits while cumulative $\mathrm{CO}_{2}$ emissions are compared to the type-approval $\mathrm{CO}_{2}$ emission values over NEDC.

As a window analysis alone cannot explain individual phenomena in the emission traces there is a need for a more detailed analysis. Hence the third analysis in this section covers the instantaneous emission traces. This analysis is performed with a high temporal resolution, which allows a more accurate insight into time-resolved phenomena of the emissions trace. Instantaneous emission results of $\mathrm{CH}_{4}, \mathrm{THC}, \mathrm{CO}$, and $\mathrm{NO}_{\mathrm{x}}$ are presented in conjunction with the corresponding exhaust gas temperature and mass flow measurements, which is beneficial as it provides an insight into the thermal history of the engine and the aftertreatment system. Additionally, the aforementioned results are amended by traces of velocity, altitude and the air- 
Cite this paper as: Davor Rašić, Samuel Rodman Oprešnik, Tine Seljak, Rok Vihar, Urban Žvar Baškovič, Tomaž Wechtersbach, Tomaž Katrašnik, RDE-based assessment of a factory bi-fuel CNG/gasoline light-duty vehicle, Atmospheric Environment, Volume 167, 2017, Pages 523-541, ISSN 1352-2310, https://doi.org/10.1016/j.atmosenv.2017.08.055.

to-fuel ratio $(\lambda)$. Instantaneous velocity provides a useful characterization of the driving pattern, whereas the air-to-fuel ratio provides an insight into the composition of the in-cylinder charge and thus of exhaust emissions. The altitude reflects the road gradient, which in combination with the velocity and the accelerometer reading provides an insight into the power demand of the vehicle. For analysis purposes, the instantaneous emission results, except $\mathrm{CO}$ emissions, of each route using both fuel options will be presented on the same scale and with the same accuracy level.

\subsection{WLTC test results}

In order to minimize the influence of the potential road gradient and wind, the WLTC cycles were driven twice on the same flat road, once in every direction. Emissions of both test runs were averaged. Measurement results of each WLTC section are presented in Table 5. The most interesting data for the RDE evaluation is the cumulative WLTC $\mathrm{CO}_{2}$ mass value, which in the analyzed case sums up to $5072 \mathrm{~g}$. According to the EMROAD procedure, half of this value is used as $\mathrm{CO}_{2} \mathrm{MAW}$ reference value used for RDE verification of routes driven with $\mathrm{CNG}$.

Table 5. WLTC emissions of individual WLTC sections (presented in Fig. 1) and cumulative WLTC emissions with CNG

\begin{tabular}{|l|l|l|l|l|l|}
\hline & Low & Medium & High & Extra High & Cumulative \\
\hline Gas & Mass [g] & Mass [g] & Mass [g] & Mass [g] & Mass [g] \\
\hline $\mathrm{CH}_{4}$ & $1.9 \cdot 10^{-3}$ & $5.8 \cdot 10^{-3}$ & $10.2 \cdot 10^{-3}$ & $46.7 \cdot 10^{-3}$ & $64.6 \cdot 10^{-3}$ \\
\hline $\mathrm{CO}$ & 1.447 & 1.926 & 1.880 & 2.136 & 7.389 \\
\hline $\mathrm{CO}_{2}$ & 740.4 & 1044 & 1405 & 1882 & 5072 \\
\hline $\mathrm{NMHC}$ & $2.8 \cdot 10^{-3}$ & $2.1 \cdot 10^{-3}$ & $2.4 \cdot 10^{-3}$ & $0.6 \cdot 10^{-3}$ & $7.9 \cdot 10^{-3}$ \\
\hline $\mathrm{NO}$ & 0.046 & 0.047 & 0.102 & 0.302 & 0.497 \\
\hline $\mathrm{NO}_{2}$ & $10.2 \cdot 10^{-3}$ & $5.3 \cdot 10^{-3}$ & $14.4 \cdot 10^{-3}$ & $10.8 \cdot 10^{-3}$ & $40.7 \cdot 10^{-3}$ \\
\hline $\mathrm{NO}_{\mathrm{x}}$ & 0.056 & 0.052 & 0.116 & 0.313 & 0.537 \\
\hline $\mathrm{O}_{2}$ & 101.1 & 82.82 & 124.4 & 121.3 & 429.6 \\
\hline $\mathrm{THC}$ & $4.7 \cdot 10^{-3}$ & $7.9 \cdot 10^{-3}$ & $12.6 \cdot 10^{-3}$ & $47.3 \cdot 10^{-3}$ & $72.5 \cdot 10^{-3}$ \\
\hline
\end{tabular}

In [17], a vehicle with an almost identical SI engine and comparable mass was tested and it was reported that the engine emitted $27.88 \%$ more $\mathrm{CO}_{2}$ when using gasoline than when using CNG. Therefore, it can be estimated that cumulative WLTC $\mathrm{CO}_{2}$ emissions of the vehicle analyzed in this paper while using gasoline equal approximately $127.88 \%$ of WLTC $\mathrm{CO}_{2}$ emissions while using CNG thus yielding a value of $6486 \mathrm{~g}$.

\subsection{Emissions of the RDE Moderate route}

Table 6. Real-world driving emissions using CNG and gasoline compared to type-approval and Euro 5 emission limits for the RDE Moderate route

\begin{tabular}{|l|l|l|l|l|}
\hline & CNG & Gasoline & Type-approval & Euro 5 limit \\
\hline$M_{C O}[\mathrm{mg} / \mathrm{km}]$ & 164.37 & 3474.2 & 376.8 & 1810 \\
\hline$M_{\mathrm{THC}}[\mathrm{mg} / \mathrm{km}]$ & 4.16 & 12.6 & 29.4 & 130 \\
\hline$M_{N M H C}[\mathrm{mg} / \mathrm{km}]$ & 0.38 & 4.07 & N.A. & 68 \\
\hline$M_{\mathrm{NO}_{x}}[\mathrm{mg} / \mathrm{km}]$ & 11.73 & 5.88 & 16.8 & 75 \\
\hline$M_{\mathrm{CO}_{2}}[\mathrm{~g} / \mathrm{km}]$ & 166.91 & 260.28 & 156 & unregulated \\
\hline$M_{\mathrm{CH}_{4}}[\mathrm{mg} / \mathrm{km}]$ & 3.78 & 8.58 & N.A. & unregulated \\
\hline
\end{tabular}


Cite this paper as: Davor Rašić, Samuel Rodman Oprešnik, Tine Seljak, Rok Vihar, Urban Žvar Baškovič, Tomaž Wechtersbach, Tomaž Katrašnik, RDE-based assessment of a factory bi-fuel CNG/gasoline light-duty vehicle, Atmospheric Environment, Volume 167, 2017, Pages 523-541, ISSN 1352-2310, https://doi.org/10.1016/j.atmosenv.2017.08.055.

\begin{tabular}{|l|l|l|l|l|}
\hline$M_{N O}[\mathrm{mg} / \mathrm{km}]$ & 9.85 & 5.12 & N.A. & unregulated \\
\hline$M_{\mathrm{NO}_{2}}[\mathrm{mg} / \mathrm{km}]$ & 1.88 & 0.75 & N.A. & unregulated \\
\hline
\end{tabular}

Table 6 presents the real-world driving emissions using CNG and gasoline compared to type-approval and Euro 5 emission limits for the RDE Moderate route using CNG and gasoline. Results in Table 6 indicate that the $\mathrm{THC}$ and $\mathrm{NO}_{\mathrm{x}}$ emissions when using both fuel options are within the type-approval and Euro 5 limits. Additionally, it can be seen that the NMHC emissions when using both fuel options are within the Euro 5 emission limits. The $\mathrm{CO}$ emissions when using gasoline are nearly a factor of two higher than the Euro 5 emission limits and a factor of nine higher than the type-approval limits, while the $\mathrm{CO}$ emissions when using $\mathrm{CNG}$ are within the type-approval and Euro 5 emission limits. The $\mathrm{CO}_{2}$ emissions when using both fuel options exceed the type-approval limit. Reasoning and insight into these results will be elaborated in the following sections.

\subsubsection{Window analysis}

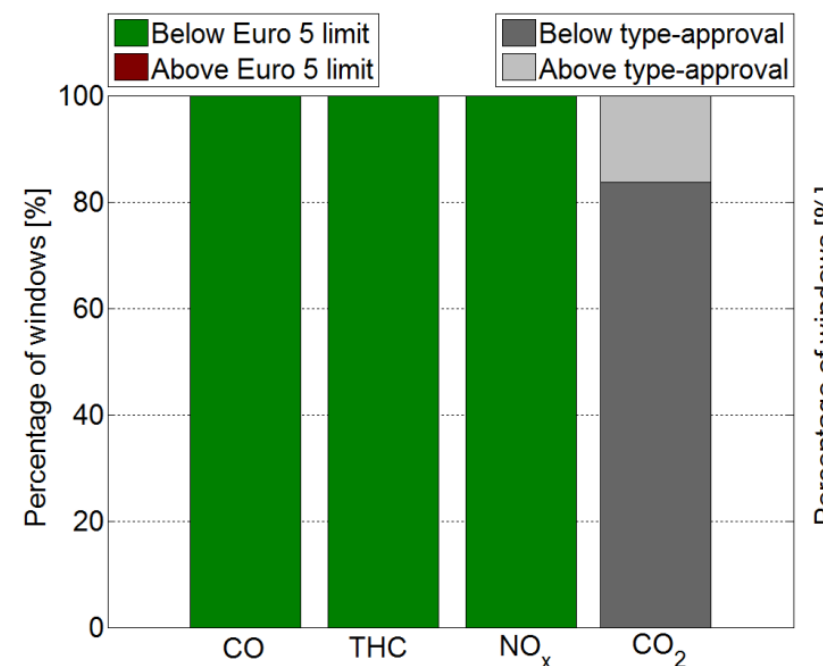

a.)

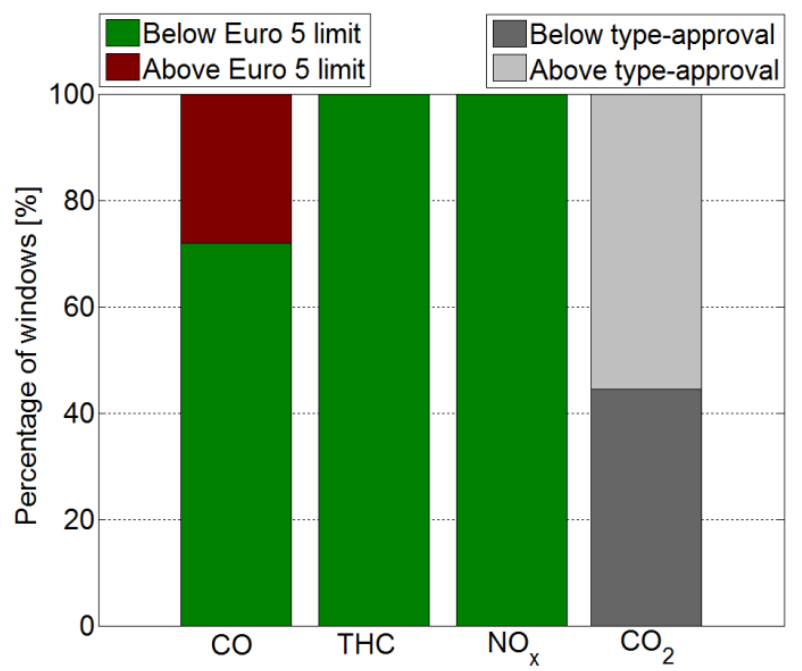

b.)

Fig. 3. Evaluation of windowed emissions compared to Euro 5 emission limits and typeapproval $\mathrm{CO}_{2}$ values for $\mathrm{RDE}$ Moderate route using a.) $\mathrm{CNG}$ and b.) gasoline fuel

Fig. 3 presents an evaluation of windowed emissions compared to Euro 5 emission limits and type-approval $\mathrm{CO}_{2}$ values for the RDE Moderate route. From Fig. 3a, it can be seen that emissions of $\mathrm{CO}, \mathrm{THC}$, and $\mathrm{NO}_{\mathrm{x}}$ when using $\mathrm{CNG}$ of all individual windows are below Euro 5 limit confirming the results in Table 6. Almost $20 \%$ of individual windows recorded $\mathrm{CO}_{2}$ emissions above type-approval value. From Fig. 3b, it can be seen that roughly $30 \%$ of individual windows record $\mathrm{CO}$ emissions above Euro 5 limit when using gasoline. THC and $\mathrm{NO}_{\mathrm{x}}$ emissions of all individual windows when using gasoline are below Euro 5 limit. $\mathrm{CO}_{2}$ emissions results from Table 6 when using gasoline are explained by the fact that almost $60 \%$ of individual windows record $\mathrm{CO}_{2}$ emissions above type-approval, which is expected as the vehicle was type-approved using CNG.

The instantaneous emission analysis presented in Section 3.2.2 provides more detailed reasoning of the time intervals of the RDE Moderate route at which the individual windows recorded above type-approval/Euro 5 limit values of the measured emissions. 
Cite this paper as: Davor Rašić, Samuel Rodman Oprešnik, Tine Seljak, Rok Vihar, Urban Žvar Baškovič, Tomaž Wechtersbach, Tomaž Katrašnik, RDE-based assessment of a factory bi-fuel CNG/gasoline light-duty vehicle, Atmospheric Environment, Volume 167, 2017, Pages 523-541, ISSN 1352-2310,

https://doi.org/10.1016/j.atmosenv.2017.08.055.

\subsubsection{Instantaneous emission analysis}

a.)

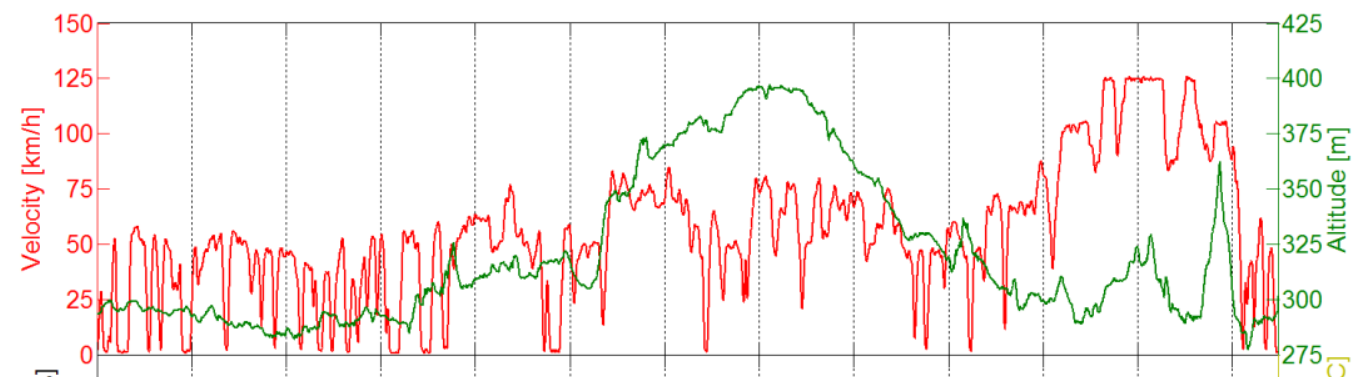

b.)

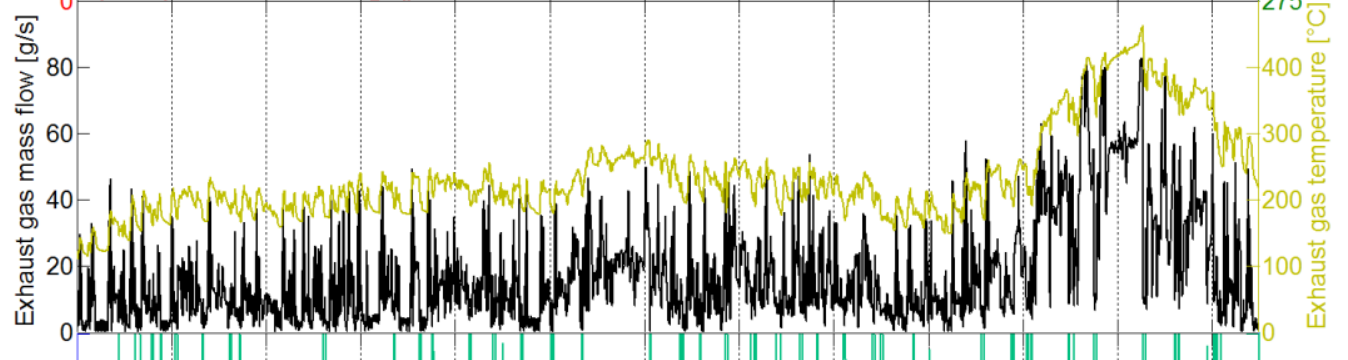

c.) $250-$

E $200-$

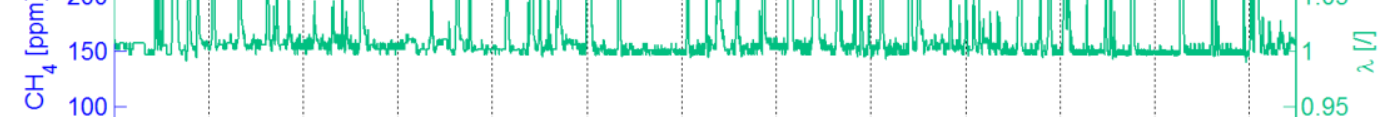

d.)

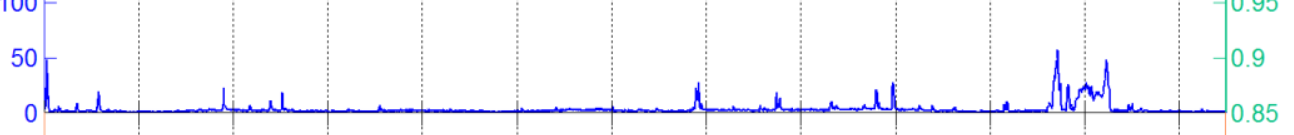

e.)
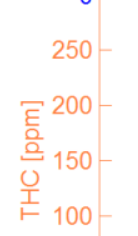

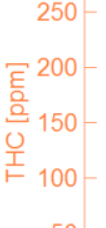
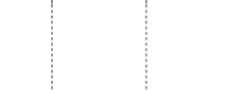
Cite this paper as: Davor Rašić, Samuel Rodman Oprešnik, Tine Seljak, Rok Vihar, Urban Žvar Baškovič, Tomaž Wechtersbach, Tomaž Katrašnik, RDE-based assessment of a factory bi-fuel CNG/gasoline light-duty vehicle, Atmospheric Environment, Volume 167, 2017, Pages 523-541, ISSN 1352-2310, https://doi.org/10.1016/j.atmosenv.2017.08.055.

Fig. 4 summarizes the most relevant time traces of the vehicle, engine and emission parameters that are required to establish interrelation between listed parameters and to reason observed emission trends for the RDE Moderate route using CNG. In Fig. 4c and 4d, it can be observed that the shape of time traces of the $\mathrm{CH}_{4}$ and THC emission quantitatively coincide, which is expected. Peaks of both emissions until 1500s are mainly a consequence of sudden load decreases and increases combined with corresponding temperature fluctuations around the catalyst temperature being at the edge of the light-off temperature, which is indicated by the time trace of the exhaust gas (EG) temperature in Fig. 4b. The $\mathrm{CH}_{4}$ and THC emissions feature higher values also in the time interval between 3400 s and $4500 \mathrm{~s}$, which correlates to the downhill driving (Fig. 4a). In this regime, low engine loads lead to the reduction of the catalyst temperature, hindering a successful conversion in TWC. Further peaks of both emissions can be observed between 5000s and 6000s. These emission peaks primarily correlate with rapid load and consequently EG mass flow increases seen in Fig. 4b. Furthermore, within this time window, the engine power frequently exceeds maximum engine power attained during the NEDC cycle since, as discernible in Fig. 4a. In this time window, the vehicle was operated on the motorway with varying vehicle velocity and road gradient. This indicates a potential $\mathrm{CH}_{4}$ and THC breakthrough, as engine power and thus velocities in the TWC in these operating regimes exceeded the maximum engine power attained during the NEDC cycle being, in general, a sizing guideline for the TWC. Further effects that contribute to these $\mathrm{CH}_{4}$ and THC emission trends can be summarized as retarded ignition timing to prevent knock and increased engine speed. Both effects namely contribute to higher engine-out $\mathrm{CH}_{4}$ and $\mathrm{THC}$ emissions.

From the comparison of Fig. $4 \mathrm{c}$ and Fig. $4 \mathrm{~d}$, it can be observed that $\mathrm{CH}_{4}$ emissions account for most of the THC emissions, which is in agreement with the results in Table 6. This is also an expected trend considering the fuel composition, whereas this further reasons relatively high TWC temperatures that are required to attain high conversion of the $\mathrm{CH}_{4}[26,36]$.

In Fig. 4e two types of $\mathrm{CO}$ emission peaks can be observed. The first type of $\mathrm{CO}$ peaks is characterized by rapid increases and decreases of the $\mathrm{CO}$ emission that correlate to THC peaks and are observed during motorway driving at high engine loads (in the time interval around 5000s). The reasoning of these realistic CO emission peaks is thus similar as of the ones for the THC emission during the motorway driving. The second type of $\mathrm{CO}$ emission peaks, which is observed much more often, is associated with the rapid rise following with an exponential fall of the $\mathrm{CO}$ emission and can be seen throughout the entire RDE-based route. The unusual shape of these peaks, their very long decay times and missing correlation of their occurrence with the relative air-to-fuel ratio $(\lambda)$ or temperature and velocity in the TWC, lead to the hypothesis that these peaks are a misconstrue generated by the NDIR analyzer. The reasoning of this falsity is explained with the strong interference of $\mathrm{CO}$ and $\mathrm{N}_{2} \mathrm{O}$ infrared absorption bands as elaborated in Section 3.4 and Appendix C, whereas, the paper also suggests a plausible route for $\mathrm{N}_{2} \mathrm{O}$ formation considering engine-out emissions and chemical kinetics in the TWC specific to the use of CNG being elaborated Section 3.4 and in Appendix B.

When analyzing $\mathrm{NO}_{\mathrm{x}}$ emissions, it is worth mentioning that when using $\mathrm{CNG}$ the engine does not enrich the combustion mixture to $\lambda$ under 1 , which combined with the earlier ignition causes high cylinder temperature, both favoring $\mathrm{NO}_{\mathrm{x}}$ formation. Instantaneous $\mathrm{NO}_{\mathrm{x}}$ emissions are presented in Fig. 4f. $\mathrm{NO}_{\mathrm{x}}$ emission peaks are mostly a consequence of sudden load decreases and increases. They mostly coincide with lean air-to-fuel ratios $(\lambda)$, which can be seen throughout the entire time interval of the RDE, since the conversion efficiency of $\mathrm{NO}_{\mathrm{x}}$ in a TWC is considerably reduced at lean operating conditions [33]. In addition, $\mathrm{NO}_{\mathrm{x}}$ emission peaks until 5000s can also be reasoned with lower TWC temperatures being at the edge of the light-off temperature. Lower TWC temperatures can be argued with the driver being less aggressive and the RDE Moderate route proving to be on the lower bound of the vehicle power 
Cite this paper as: Davor Rašić, Samuel Rodman Oprešnik, Tine Seljak, Rok Vihar, Urban Žvar Baškovič, Tomaž Wechtersbach, Tomaž Katrašnik, RDE-based assessment of a factory bi-fuel CNG/gasoline light-duty vehicle, Atmospheric Environment, Volume 167, 2017, Pages 523-541, ISSN 1352-2310,

https://doi.org/10.1016/j.atmosenv.2017.08.055.

demand in the first 5000s of the RDE Moderate route. Higher $\mathrm{NO}_{x}$ peaks from 5000s to 6000s are associated with higher loads, indicated by high EG mass flows and temperature. Since the EG temperature chart illustrated in Fig. $4 \mathrm{~b}$ indicates sufficiently high TWC temperatures for successful $\mathrm{NO}_{\mathrm{x}}$ conversion, the higher $\mathrm{NO}_{\mathrm{x}}$ emissions peaks within this time window suggest a potential $\mathrm{NO}_{\mathrm{x}}$ breakthrough and consequently a similar interpretation for higher emissions after TWC as given for the $\mathrm{CH}_{4}$ and THC emissions within this time frame.

a.)

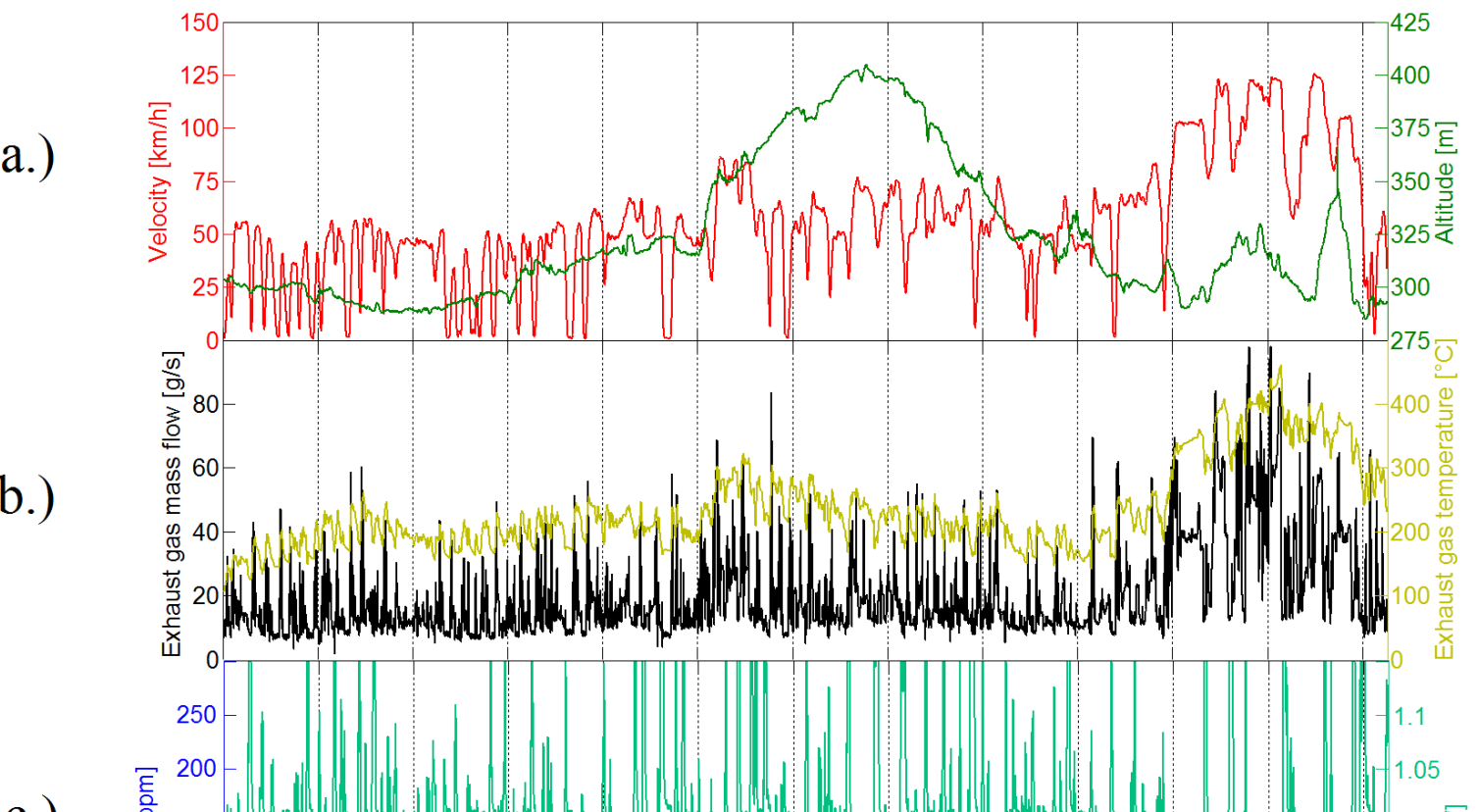

b.)

c.)

$$
{\stackrel{\text { 은 }}{{ }^{\top}}}^{\top}
$$

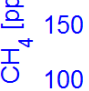

$50-$

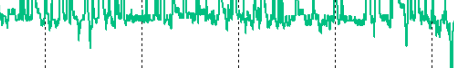


Cite this paper as: Davor Rašić, Samuel Rodman Oprešnik, Tine Seljak, Rok Vihar, Urban Žvar Baškovič, Tomaž Wechtersbach, Tomaž Katrašnik, RDE-based assessment of a factory bi-fuel CNG/gasoline light-duty vehicle, Atmospheric Environment, Volume 167, 2017, Pages 523-541, ISSN 1352-2310, https://doi.org/10.1016/j.atmosenv.2017.08.055.

Fig. 5. Instantaneous on-road emissions of RDE Moderate route using gasoline: a) velocity and altitude profile, b) exhaust gas mass flow and temperature, c.) $\mathrm{CH}_{4}$ emissions and $\lambda$, d.) $\mathrm{THC}$ emissions, e.) $\mathrm{CO}$ emissions, f.) $\mathrm{NO}_{\mathrm{x}}$ emissions

Fig. 5 summarizes the most relevant time traces of the vehicle, engine and emission parameters that are required to establish interrelation between listed parameters and to reason observed emission trends for the RDE Moderate route using gasoline. In Fig. 5c and 5d, it can be seen that the shape of time traces of the $\mathrm{CH}_{4}$ and $\mathrm{THC}$ emission coincide, but in contrast to the CNG use where THC emissions consist primarily of $\mathrm{CH}_{4}$ being mainly unburned fuel, it can be seen that peaks of the THC emissions are significantly higher than those of the $\mathrm{CH}_{4}$ emissions using gasoline, where $\mathrm{CH}_{4}$ is mainly formed during the combustion process from higher hydrocarbons. The results in Table6 further support this claim. When analyzing both traces, it can be observed that the $\mathrm{CH}_{4}$ and THC emission peak at the start of the route is a consequence of a sudden load increase combined with low conversion rates in the TWC. Notable $\mathrm{CH}_{4}$ and THC emission peaks do not emerge until the start of the uphill (in the time interval around 2600s) where a rapid increase in vehicle velocity and road grade is detected, denoting high load and rich mixture first yielding more engine-out $\mathrm{CH}_{4}$ and $\mathrm{THC}$ emissions due to a lack of oxygen and further hindering their conversion efficiency in the TWC [33]. In addition, during this high load operating regime using gasoline, spark timing is further retarded compared to the use of CNG due to relatively high compression ratio designed for use of the CNG. It can be seen that higher $\mathrm{CH}_{4}$ and THC emission peaks re-emerge at 5000s, roughly when the vehicle entered the motorway. Within the time window of motorway operation (between 5000s and 6000s) the engine frequently exceeds maximum engine power attained during the NEDC cycle indicating rich mixture phases combined with retarded spark timing as well as potential $\mathrm{CH}_{4}$ and THC breakthrough. Apart from the aforementioned sections of the RDE-based route where the vehicle was under high load and operated with belowstoichiometric $\lambda$, it can be seen that the emissions of $\mathrm{CH}_{4}$ and THC during the rest of the RDEbased route were nearly negligible, denoting good performance of the engine and the TWC.

Instantaneous $\mathrm{CO}$ emissions are presented in Fig. 5e. It can be seen that the $\mathrm{CO}$ emissions are mainly characterized by the trend of $\lambda$ and thus rich mixture, which is expected as the lack of oxygen and retarded spark timing yield more engine-out $\mathrm{CO}$ emissions and their subsequent lower conversion efficiency in a TWC [33]. The CO emission peaks hence reach higher values within the time intervals of higher loads (the ascent between 2500s and 3000s and motorway operation between 5000s and 6000s). It is important to note that, in contrast to $\mathrm{CO}$ emissions traces when using $\mathrm{CNG}$ as a fuel, the $\mathrm{CO}$ emissions traces when using gasoline do not feature the presumably false $\mathrm{CO}$ peaks characterized by the rapid rise following with an exponential fall and missing correlation with the relative air-to-fuel ratio $(\lambda)$ or temperature and velocity in the TWC. Additionally, the CO emission traces were inspected with a roughly $20 \mathrm{x}$ magnification to account for higher display scales of $\mathrm{CO}$ emission traces when using gasoline compared to when using CNG. It can be reported that no $\mathrm{CO}$ measurement errors nor any indication of $\mathrm{CO}$ measurements errors being masked by the higher $\mathrm{CO}$ scale were observed. Therefore, it can be assumed with high certainty that the measuring error detected when using $\mathrm{CNG}$ is not present for the use of gasoline.

Instantaneous $\mathrm{NO}_{\mathrm{x}}$ emissions are presented in Fig. 5f. It can be seen that the $\mathrm{NO}_{\mathrm{x}}$ emission peaks from 0 s to 5000 s mostly correlate with lean air-to-fuel ratios $(\lambda)$ and with low TWC temperatures being at the edge of the light-off temperature. Similar to the $\mathrm{NO}_{\mathrm{x}}$ peaks between 5000s and 6000s when using $\mathrm{CNG}$, it can be seen that the $\mathrm{NO}_{\mathrm{x}}$ peaks within this time interval are also associated with higher loads when using gasoline, indicating a potential $\mathrm{NO}_{\mathrm{x}}$ breakthrough. Furthermore, it is important to note that lower cumulative values of the $\mathrm{NO}_{\mathrm{x}}$ 
Cite this paper as: Davor Rašić, Samuel Rodman Oprešnik, Tine Seljak, Rok Vihar, Urban Žvar Baškovič, Tomaž Wechtersbach, Tomaž Katrašnik, RDE-based assessment of a factory bi-fuel CNG/gasoline light-duty vehicle, Atmospheric Environment, Volume 167, 2017, Pages 523-541, ISSN 1352-2310, https://doi.org/10.1016/j.atmosenv.2017.08.055.

emissions when using gasoline in general result from lower engine-out $\mathrm{NO}_{\mathrm{x}}$ emissions being mainly influenced by rich mixture and retarded spark timing both reducing engine-out $\mathrm{NO}_{\mathrm{x}}$ emissions and further by their higher conversion efficiency in TWC due to high $\mathrm{CO}$ and low or nearly negligible $\mathrm{O}_{2}$ concentration promoting $\mathrm{NO}$ reactions with $\mathrm{CO}$.

\subsection{Emissions of the RDE Extended route}

Table 7. RDE Extended route emissions using CNG and gasoline compared to type-approval and Euro 5 emission limits

\begin{tabular}{|l|l|l|l|l|}
\hline & CNG & Gasoline & Type-approval & Euro 5 limit \\
\hline$M_{C O}[\mathrm{mg} / \mathrm{km}]$ & 227.82 & 4385.6 & 376.8 & 1810 \\
\hline$M_{\mathrm{THC}}[\mathrm{mg} / \mathrm{km}]$ & 18.20 & 12.96 & 29.4 & 130 \\
\hline$M_{N M H C}[\mathrm{mg} / \mathrm{km}]$ & 3.14 & 2.38 & N.A. & 68 \\
\hline$M_{N O_{x}}[\mathrm{mg} / \mathrm{km}]$ & 15.50 & 8.89 & 16.8 & 75 \\
\hline$M_{C O_{2}}[\mathrm{~g} / \mathrm{km}]$ & 212.52 & 289.22 & 156 & unregulated \\
\hline$M_{C H_{4}}[\mathrm{mg} / \mathrm{km}]$ & 15.06 & 10.58 & N.A. & unregulated \\
\hline$M_{N O}[\mathrm{mg} / \mathrm{km}]$ & 14.15 & 5.69 & N.A. & unregulated \\
\hline$M_{\mathrm{NO}_{2}}[\mathrm{mg} / \mathrm{km}]$ & 1.34 & 3.19 & N.A. & unregulated \\
\hline
\end{tabular}

Table 7 presents the real-world driving emissions when using CNG and gasoline compared to type-approval and Euro 5 emission limits for the RDE Extended route when using CNG and gasoline. Results in Table 7 indicate that the THC and $\mathrm{NO}_{\mathrm{x}}$ emissions when using both fuel options are within the type-approval and Euro 5 limits. Additionally, it can be seen that the NMHC emissions when using both fuel options are within the Euro 5 emission limits. The CO emissions when using gasoline are nearly 2.5 times higher than the Euro 5 emission limits and nearly 12 times higher than the type-approval limits, while the $\mathrm{CO}$ emissions when using $\mathrm{CNG}$ are within the type-approval and Euro 5 limits. The $\mathrm{CO}_{2}$ emissions when using both fuel options exceed the type-approval limit, which is obvious due to the driving pattern. Reasoning and insight into these results will be elaborated in the following sections.

The comparison of RDE Moderate route emissions given in Table 6 to the RDE Extended route emissions presented in Table 7 reveals that when using CNG values of all of the monitored emissions except $\mathrm{NO}_{2}$ have notably increased. A similar comparison for the gasoline fuel reveals that THC and NO emissions feature similar values for both routes, NMHC emission feature significant decrease for the RDE Extended route, while all other emissions have notably increased for the RDE Extended route. Compared to the RDE Moderate route when using CNG it can be seen that the $\mathrm{CO}_{2}$ emissions of the RDE Extended route when using CNG have risen by $27 \%$, whereas the $\mathrm{CO}_{2}$ emissions when using gasoline have risen by only $11 \%$. This phenomenon can be explained by the decrease in the difference of the retarded ignition timing between using CNG and gasoline in the RDE Extended route compared to the RDE Moderate route. 
Cite this paper as: Davor Rašić, Samuel Rodman Oprešnik, Tine Seljak, Rok Vihar, Urban Žvar Baškovič, Tomaž Wechtersbach, Tomaž Katrašnik, RDE-based assessment of a factory bi-fuel CNG/gasoline light-duty vehicle, Atmospheric Environment, Volume 167, 2017, Pages 523-541, ISSN 1352-2310,

https://doi.org/10.1016/j.atmosenv.2017.08.055.

\subsubsection{Window analysis}

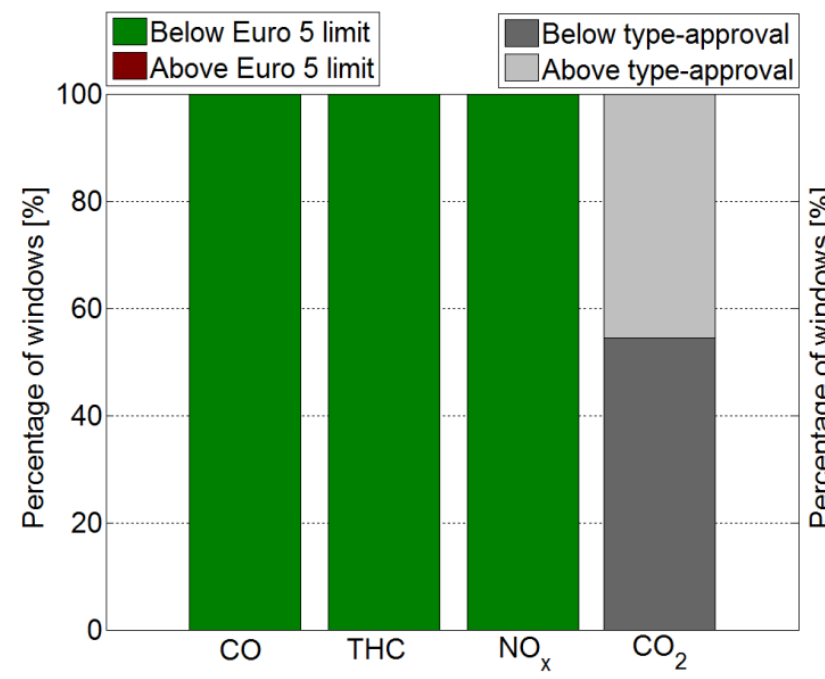

a.)

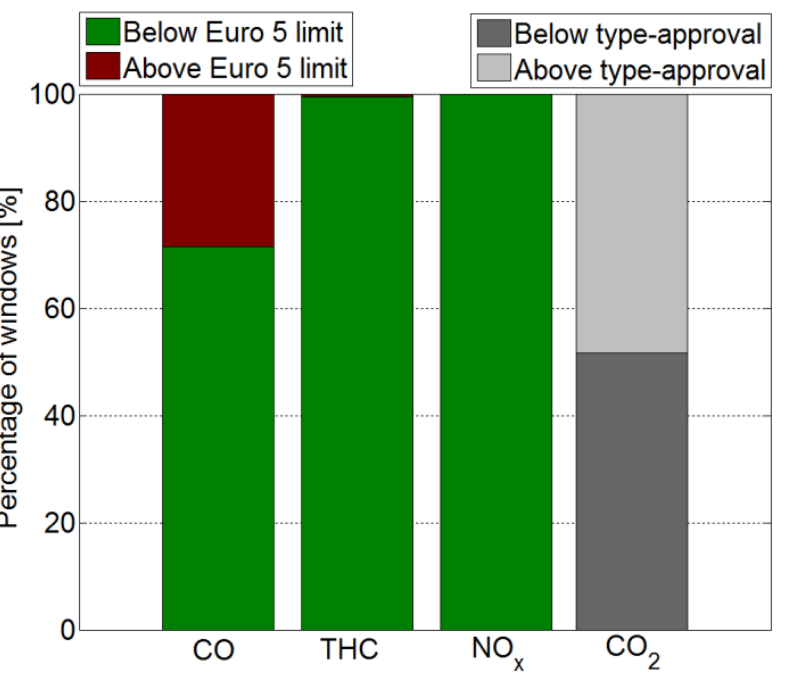

b.)

Fig. 6. RDE Extended route evaluation of windowed emissions compared to Euro 5 emission limits and type-approval $\mathrm{CO}_{2}$ values, a.) using $\mathrm{CNG}$, b.) using gasoline

Fig. 6 presents the RDE Extended route evaluation of windowed emissions compared to Euro 5 emission limits and type-approval $\mathrm{CO}_{2}$ values. From Fig. $6 \mathrm{a}$ it can be seen that emissions of $\mathrm{CO}, \mathrm{THC}$, and $\mathrm{NO}_{\mathrm{x}}$ when using CNG of all individual windows are below Euro 5 limit which confirms the results in Table 7, whereas almost $50 \%$ of individual windows recorded $\mathrm{CO}_{2}$ emissions above type-approval value. From Fig. $6 \mathrm{~b}$ it can be seen that roughly $30 \%$ of individual windows record $\mathrm{CO}$ emissions above Euro 5 limit while roughly $1 \%$ of individual windows record THC emissions above Euro 5 when using gasoline. $\mathrm{NO}_{\mathrm{x}}$ emissions of all individual windows when using gasoline are below Euro 5 limit, while $\mathrm{CO}_{2}$ emissions results from Table 7 are explained by the fact that almost $50 \%$ of individual windows record $\mathrm{CO}_{2}$ emissions above type-approval.

Analyses of instantaneous emissions are presented in Section 3.3.2 and provide more detailed reasoning of the time intervals of the RDE Extended route at which the individual windows recorded above type-approval/Euro 5 limit values of the measured emissions. 
Cite this paper as: Davor Rašić, Samuel Rodman Oprešnik, Tine Seljak, Rok Vihar, Urban Žvar Baškovič, Tomaž Wechtersbach, Tomaž Katrašnik, RDE-based assessment of a factory bi-fuel CNG/gasoline light-duty vehicle, Atmospheric Environment, Volume 167, 2017, Pages 523-541, ISSN 1352-2310,

https://doi.org/10.1016/j.atmosenv.2017.08.055.

\subsubsection{Instantaneous emission analysis}

a.)

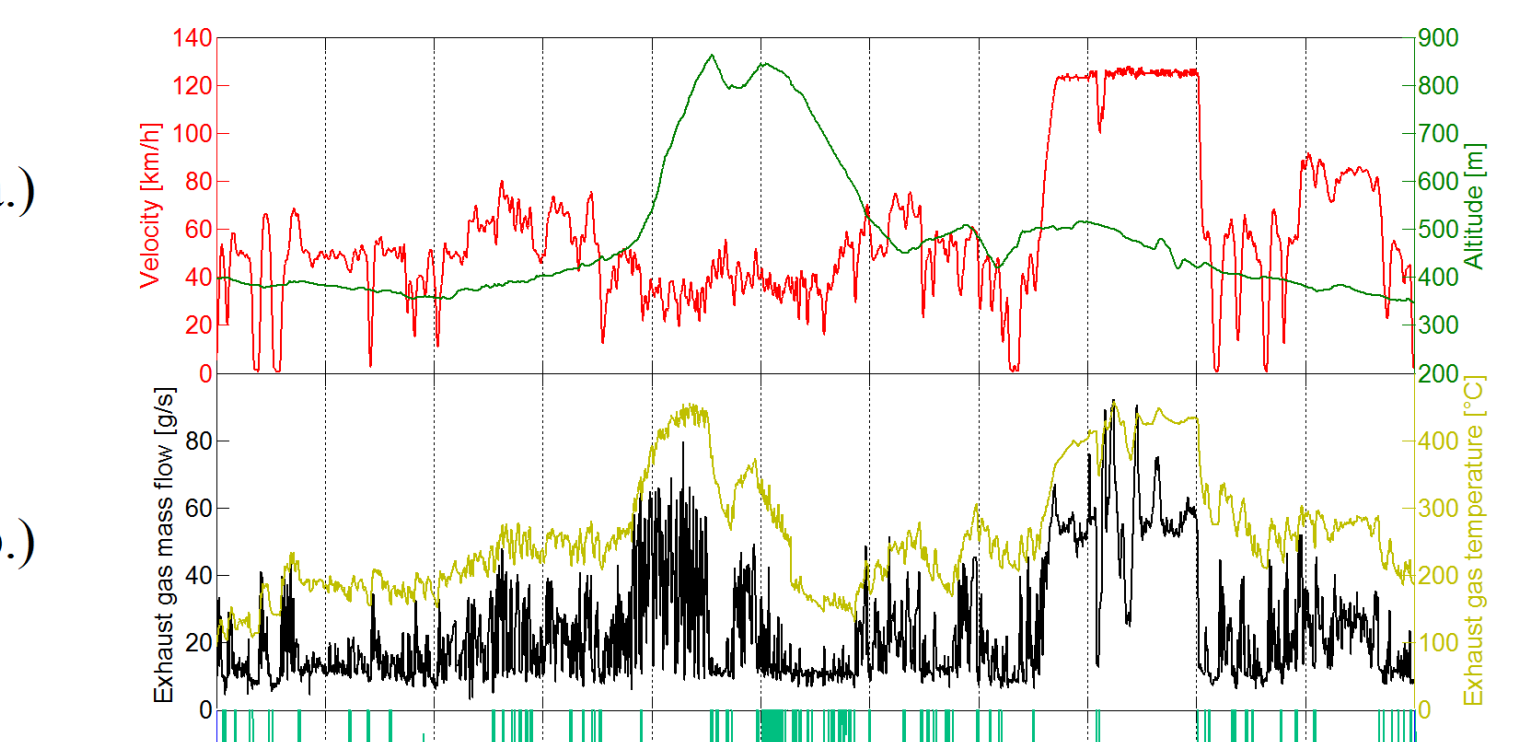

c.)

b.)

d.)

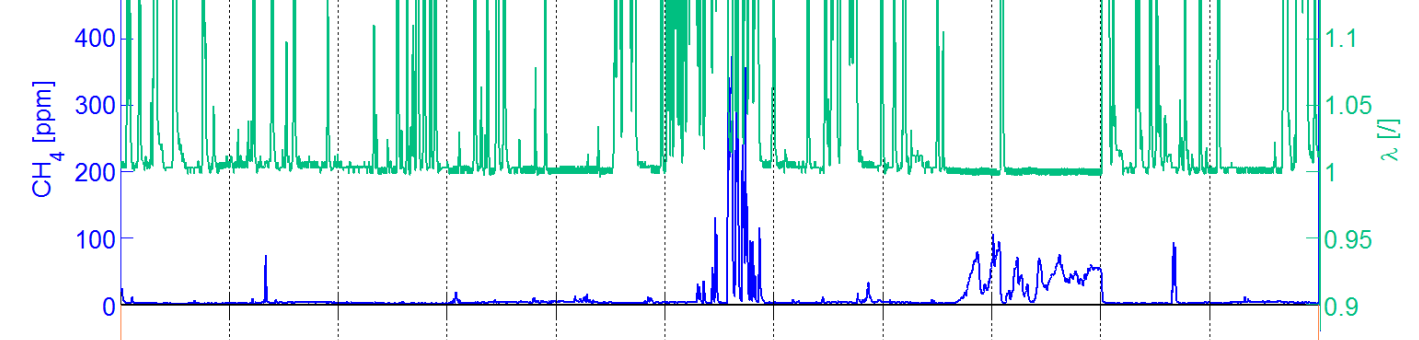

e.)

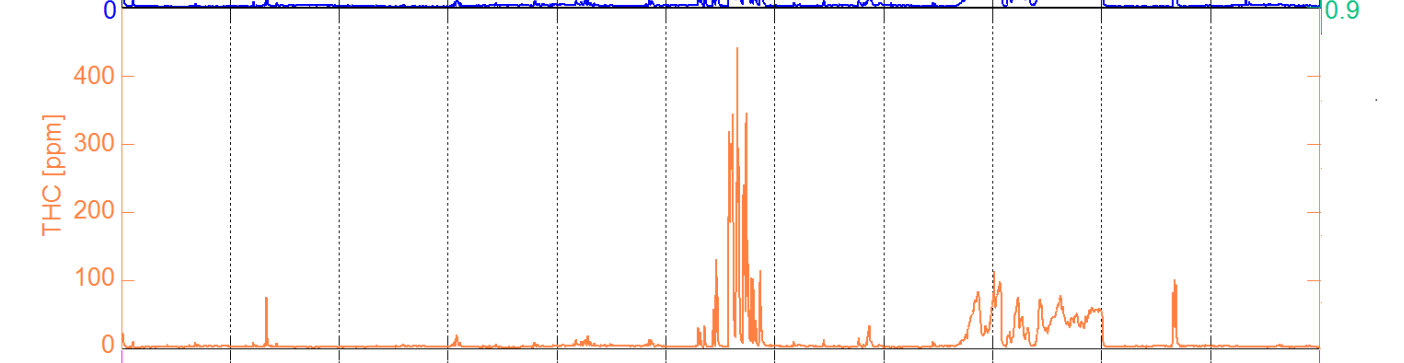

f.)
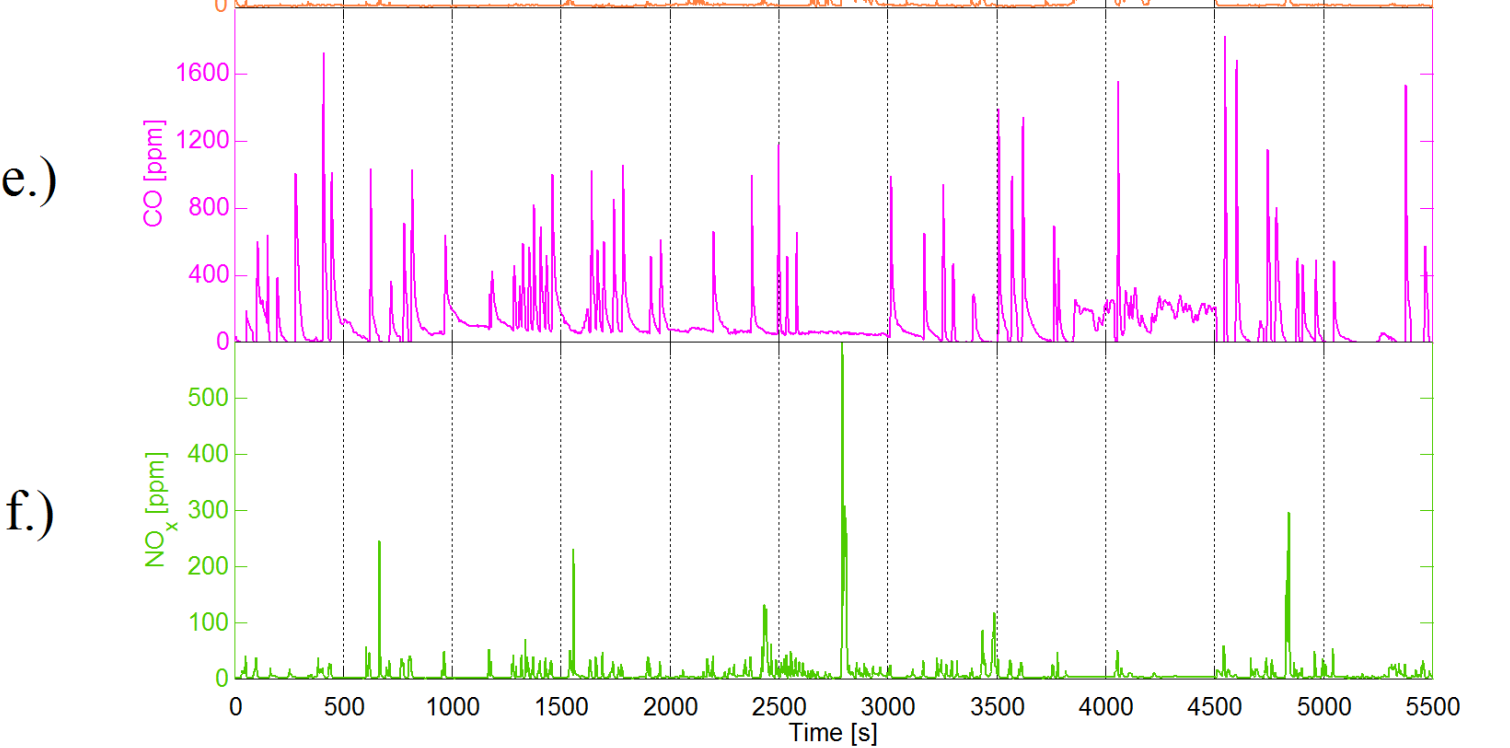

Fig. 7. Instantaneous on-road emissions of RDE Extended route using CNG: a) velocity and altitude profile, b) exhaust gas mass flow and temperature, c.) $\mathrm{CH}_{4}$ emissions and $\lambda$, d.) THC emissions, e.) $\mathrm{CO}$ emissions, f.) $\mathrm{NO}_{\mathrm{x}}$ emissions 
Cite this paper as: Davor Rašić, Samuel Rodman Oprešnik, Tine Seljak, Rok Vihar, Urban Žvar Baškovič, Tomaž Wechtersbach, Tomaž Katrašnik, RDE-based assessment of a factory bi-fuel CNG/gasoline light-duty vehicle, Atmospheric Environment, Volume 167, 2017, Pages 523-541, ISSN 1352-2310, https://doi.org/10.1016/j.atmosenv.2017.08.055.

Fig. 7 summarizes the most relevant time traces of the vehicle, engine and emission parameters that are required to establish interrelation between listed parameters and to reason observed emission trends for the RDE Extended route using CNG. The reasoning of the phenomena causing emission peaks of various gaseous emissions is similar to the interpretation laid down in section 3.2.2 (RDE Moderate route when using $\mathrm{CNG}$ ), therefore, this section will focus on explaining the phenomena, seen only in the RDE Extended route when using CNG.

In contrast to RDE Moderate route, the RDE Extended route features a longer downhill leading to higher $\mathrm{CH}_{4}$ and THC emissions. Within the time interval between $2600 \mathrm{~s}$ and 3000s, when the vehicle was descending, the engine operated in general at very low and predominantly with a lean mixture yielding high $\mathrm{CH}_{4}$ and $\mathrm{THC}$ emission. Additionally, Fig. $7 \mathrm{~b}$ indicates that the EG temperature was remarkably reduced in this section, suggesting low conversion rates in the TWC [26, 36]. Larger spark advance produces higher combustion temperatures and lower exhaust temperatures. The latter combined with a very high methane share in the THC emissions of exhaust gasses and lower efficiency of the THC conversion in the TWC due to its faster degradation and low exhaust gas temperatures results in higher THC emissions.

Low CO emissions within the time interval between 2600s and 3000s where other pollutants peaked are reasoned with high combustion temperatures since more $\mathrm{CO}$ is converted to $\mathrm{CO}_{2}$ at higher temperatures. The $\mathrm{CO}$ emissions of a CNG vehicle are typically low since the vehicle operates with stoichiometric ratio and typically does not enrich the combustion mixture below $\lambda=1$. In relation to the rest of the $\mathrm{CO}$ emission traces, it is important to note that two types of $\mathrm{CO}$ emission peaks are observed also for the RDE Extended route (Fig. 7e). Hence, analysis of $\mathrm{CO}$ emissions of both RDE-based routes suggests a similar issue with $\mathrm{CO}$ emission measurement readings when using $\mathrm{CNG}$.

In Fig. $7 \mathrm{f}$ it can be seen that the $\mathrm{NO}_{\mathrm{x}}$ emission peaks, in general, reach similar ppm values compared to the $\mathrm{NO}_{\mathrm{x}}$ emission peaks of the RDE Moderate route when using CNG. Exceptions, seen as higher $\mathrm{NO}_{\mathrm{x}}$ emission peaks occurring at 650s, 1550s and 4700s are a consequence of a rapid load increase yielding power outputs of the engine well above the NEDC range leading to the previously explained chain of events. The $\mathrm{NO}_{\mathrm{x}}$ emissions peak at $2800 \mathrm{~s}$ when the vehicle was descending is a consequence of a load increase at lean operating conditions leading to $\mathrm{NO}_{\mathrm{x}}$ breakthrough due to low EG temperatures and excess oxygen. 
Cite this paper as: Davor Rašić, Samuel Rodman Oprešnik, Tine Seljak, Rok Vihar, Urban Žvar Baškovič, Tomaž Wechtersbach, Tomaž Katrašnik, RDE-based assessment of a factory bi-fuel CNG/gasoline light-duty vehicle, Atmospheric Environment, Volume 167, 2017, Pages 523-541, ISSN 1352-2310,

https://doi.org/10.1016/j.atmosenv.2017.08.055.

a.)

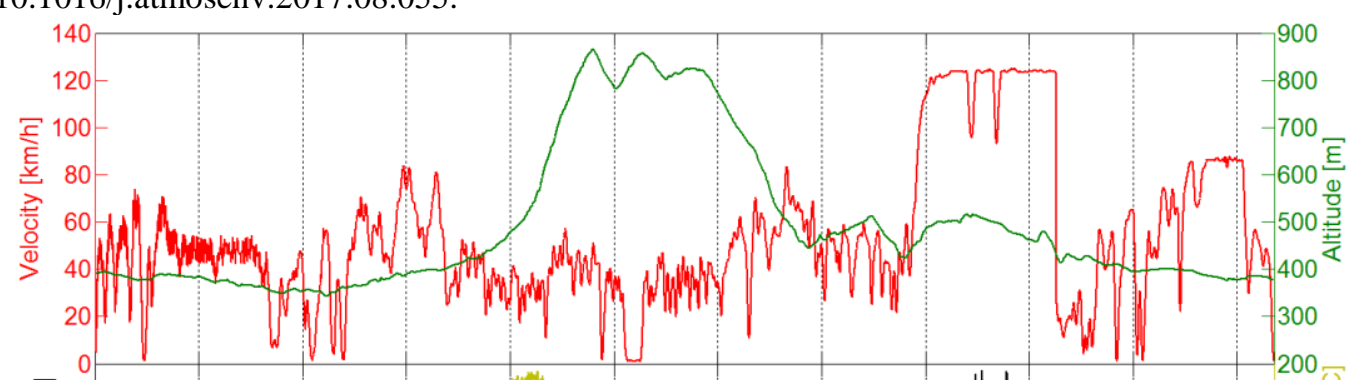

b.)

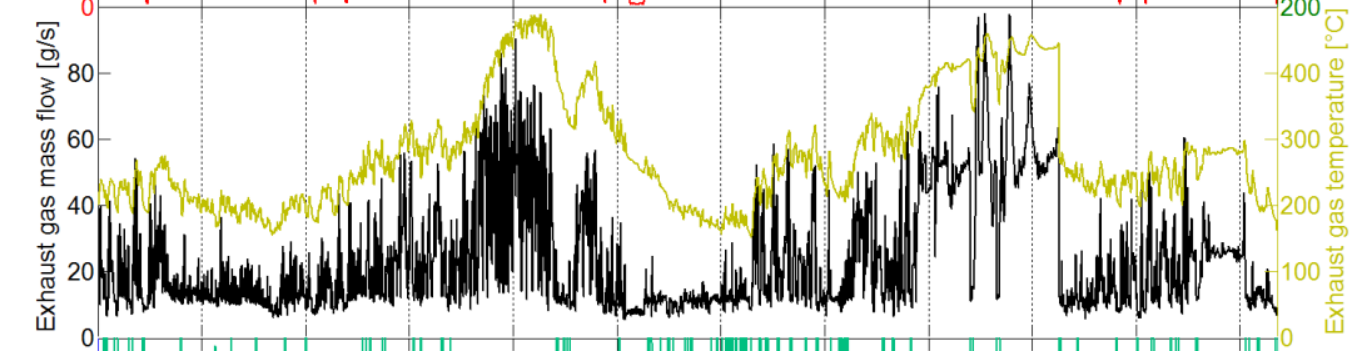

c.)

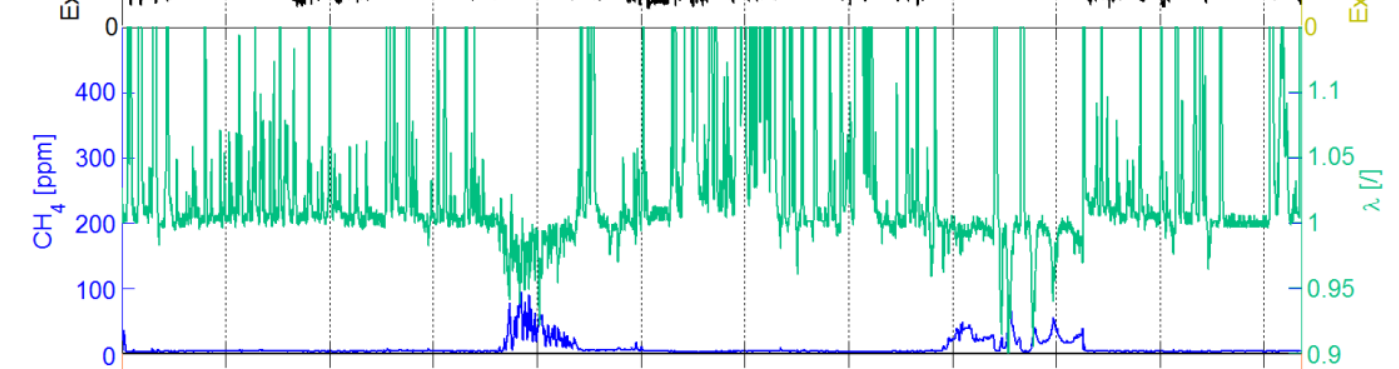

d.)

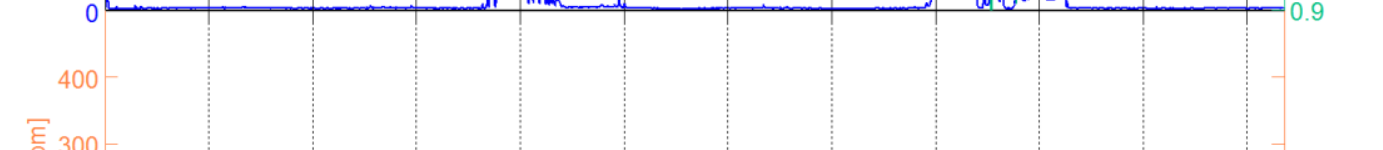

e.)

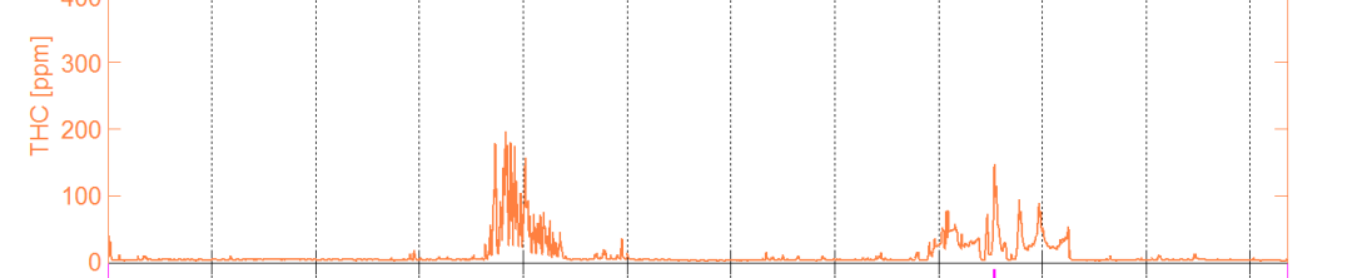

f.)

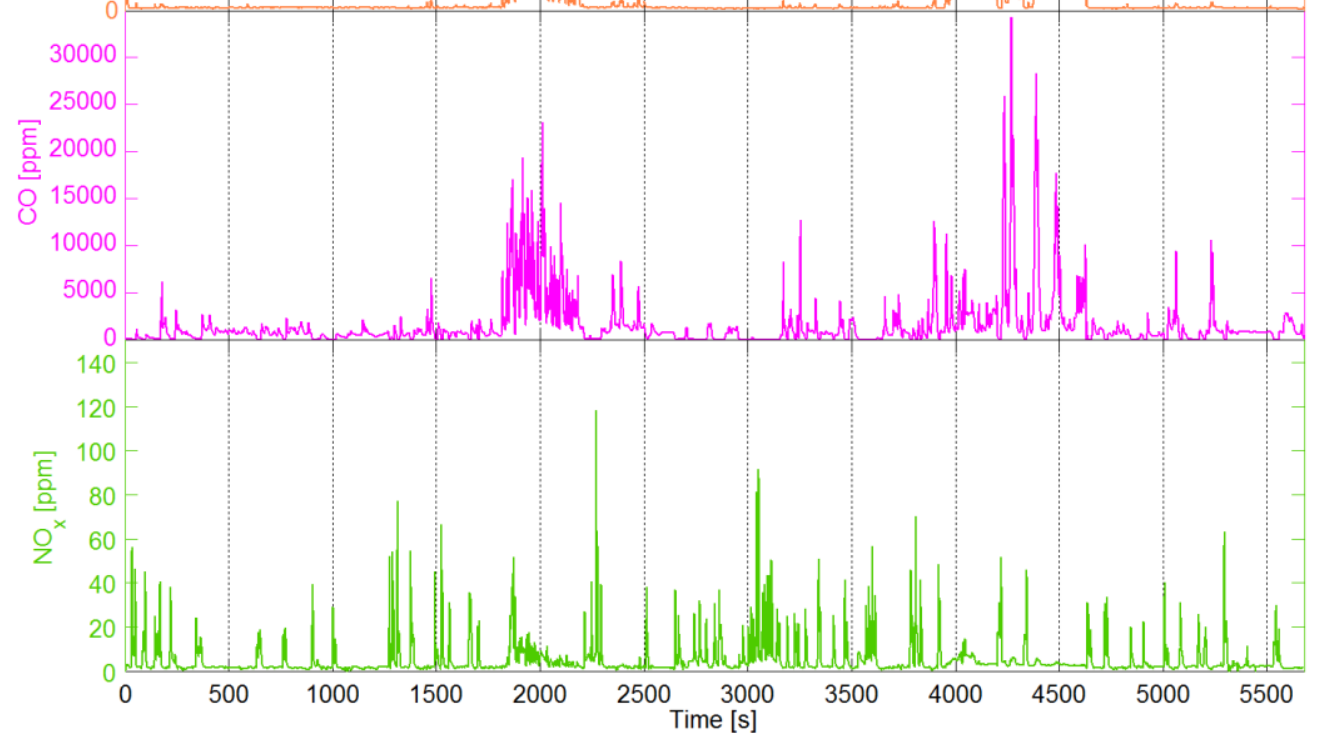

Fig. 8. Instantaneous on-road emissions of RDE Extended route using gasoline: a) velocity and altitude profile, b) exhaust gas mass flow and temperature, c.) $\mathrm{CH}_{4}$ emissions and $\lambda$, d.) $\mathrm{THC}$ emissions, e.) $\mathrm{CO}$ emissions, f.) $\mathrm{NO}_{\mathrm{x}}$ emissions 
Cite this paper as: Davor Rašić, Samuel Rodman Oprešnik, Tine Seljak, Rok Vihar, Urban Žvar Baškovič, Tomaž Wechtersbach, Tomaž Katrašnik, RDE-based assessment of a factory bi-fuel CNG/gasoline light-duty vehicle, Atmospheric Environment, Volume 167, 2017, Pages 523-541, ISSN 1352-2310, https://doi.org/10.1016/j.atmosenv.2017.08.055.

Fig. 8 summarizes the most relevant time traces of the vehicle, engine and emission parameters for analyses of time-resolved traces when using gasoline. Again, this section will focus on explaining the phenomena, seen only in the RDE Extended route when using gasoline.

Instantaneous THC emission can be observed in Fig. 8d. The RDE Extended route features a steeper and more power-demanding uphill, which explains higher THC emissions compared to the THC emissions of the RDE Moderate route in the uphill section. Apart from the ascent (between 1700s and 2300s) and the motorway section (between 3800s and 4700s), the results indicate negligible THC emissions on the rest of the RDE Extended route. The main cause of high THC emissions is again rich mixture and retarded spark timing as well as all resulting phenomena already explained previously.

In Fig. 8d it can be seen that the share of $\mathrm{CH}_{4}$ in THC emissions has risen compared to RDE Moderate, which is in agreement with the results comparison of Tables 6 and 7. This is a consequence of higher loads and richer operating conditions compared to the RDE Moderate route resulting in a more intense formation of $\mathrm{CH}_{4}$ from higher hydrocarbons during the $\mathrm{RDE}$ Extended route.

Similar to the $\mathrm{CH}_{4}$ and THC emissions, it can be seen that the $\mathrm{CO}$ emissions (Fig. 8e) are much more pronounced at high load, i.e. around $1800 \mathrm{~s}$ when the vehicle began its ascent and between 3800s and 4700s when the vehicle was driven on the motorway. The conversion efficiency of $\mathrm{CO}$ in a TWC is considerably reduced due to the rich mixture operation [33], therefore, notable $\mathrm{CO}$ emissions in sections with high loads are expected. In contrast to $\mathrm{CO}$ emissions of the RDE Extended route when using $\mathrm{CNG}$, the $\mathrm{CO}$ emissions behave in an expected manner, therefore, it can again be concluded that the measuring error seen in the $\mathrm{CO}$ emissions is not present when using gasoline. Additionally, a similar magnification inspection as conducted when analyzing the $\mathrm{CO}$ emissions of the RDE Moderate route when using gasoline was done. It revealed no irregularities nor indication of any $\mathrm{CO}$ emission measurement errors.

It can be seen that during the RDE Extended route $\mathrm{NO}_{\mathrm{x}}$ emission (Fig. 8f) peaks occur more frequently indicating more sudden load increases and decreases compared to the RDE Moderate route when using gasoline. $\mathrm{NO}_{\mathrm{x}}$ emission peaks are, in general, of similar ppm values compared to the NOx emission peaks of the RDE Moderate route using gasoline. The $\mathrm{NO}_{\mathrm{x}}$ emission peak at 2800s, when the vehicle was descending, is a consequence of a load increase at lean operating conditions leading to $\mathrm{NO}_{\mathrm{x}}$ breakthrough due to low EG temperatures and excess oxygen.

\subsection{Consistency of $\mathrm{CO}$ measurements}

When conducting measuring campaigns using a PEMS, the attention is primarily focused on cumulative emissions; hence, any unusual behavior of the instantaneous timedependent emission traces can often be overlooked. Although the cumulative $\mathrm{CO}$ emissions of both RDE-based routes when using CNG as fuel in the present analysis are well below Euro 5 emission limits, our measurement campaign reveals that a problem can occur during the measurement of $\mathrm{CO}$ emissions. Additionally, a similar trend of $\mathrm{CO}$ emissions was also present during the WLTC when using CNG as fuel and on other routes using CNG conducted on Day 4 of this measuring campaign. Figs. 4 and 7 indicate two types of $\mathrm{CO}$ emission peaks occurring during the test. The ones that show nonrealistic time dependency are characterized by a rapid rise followed by an exponential fall of the $\mathrm{CO}$ emissions. Furthermore, the nonrealistic $\mathrm{CO}$ emission peaks coincide with engine load decrease and thus very low fueling or a fuel cutoff. Under given conditions, such high levels of $\mathrm{CO}$ emissions are unlikely to occur, especially as they are not accompanied by an increase of THC emissions. As shown in Appendix C, these false positives can be with high certainty linked to the cross sensitivity of the measuring method of $\mathrm{CO}$ and $\mathrm{N}_{2} \mathrm{O}$, which could possibly be formed under these operating conditions. 
Cite this paper as: Davor Rašić, Samuel Rodman Oprešnik, Tine Seljak, Rok Vihar, Urban Žvar Baškovič, Tomaž Wechtersbach, Tomaž Katrašnik, RDE-based assessment of a factory bi-fuel CNG/gasoline light-duty vehicle, Atmospheric Environment, Volume 167, 2017, Pages 523-541, ISSN 1352-2310,

https://doi.org/10.1016/j.atmosenv.2017.08.055.

\subsection{1. $\mathrm{N}_{2} \mathrm{O}$ formation in the TWC converter of an $\mathrm{SI}$ internal combustion engine when using CNG}

Emissions of $\mathrm{N}_{2} \mathrm{O}$ from vehicles are a well-recognized environmental issue, primarily on the account of $\mathrm{N}_{2} \mathrm{O}$ being a potent greenhouse gas [38, 40, 41 and 42]. Several studies reveal that $\mathrm{N}_{2} \mathrm{O}$ can be detected in catalyst-out emissions ranging from a few tens of ppm to near 800 ppm [35, 37, 39, 40 and 42]. In [38, 40], it is reported that formation of $\mathrm{N}_{2} \mathrm{O}$ proceeds via reduction of $\mathrm{NO}$ by $\mathrm{CO}$ when $\mathrm{O}_{2}$ is present. Similarly, the study in [49] reports that $\mathrm{N}_{2} \mathrm{O}$ formation is favored under slightly lean operating conditions. The $\mathrm{N}_{2} \mathrm{O}$ formation is observed primarily during light-off at fairly low temperatures ranging from $110-400^{\circ} \mathrm{C}[38,40,42$ and 45]. In [39, 42 and 45], it is stated that $\mathrm{N}_{2} \mathrm{O}$ decomposes at temperatures over $500^{\circ} \mathrm{C}$. In [53], it is reported that under real operating conditions significant release of $\mathrm{NO}$ may take place and accordingly $\mathrm{N}_{2} \mathrm{O}$ formation is likely to occur.

The TWC converters were originally designed to reduce engine-out emissions when using gasoline. The majority of modern TWC converters used in SI internal combustion engines thus rely on Pt, Rh and Pd [26] as active metals. However, converters that have been adapted for $\mathrm{CNG}$ vehicles mainly use $\mathrm{Pd}$ catalysts, which have the highest activity for $\mathrm{CH}_{4}$ oxidation [26] and are suited to the high concentration of $\mathrm{H}_{2} \mathrm{O}$ in the exhaust gasses and to the typically transient reaction conditions that result from cycling between oxidizing and reducing conditions when using CNG. These are known to significantly influence the catalyst's activity and stability [26]. Typical exhaust gasses when using CNG are characterized by low temperatures (even below $400^{\circ} \mathrm{C}$ ) and higher amounts of $\mathrm{H}_{2} \mathrm{O}$ vapor (due to the high content of hydrogen in methane) than gasoline use. In [46] it was reported that engines with a CNG injection system suffer from $\lambda$ overshooting due to drifts of injected fuel mass caused by pressure drops in the system when adjusting to required loads. They reported that dedicated and refined control strategies capable of preventing mass mismatches, negatively affecting the aftertreatment system, are needed [46]. Furthermore, in [51] the existence of strong nonlinearities in the lower part of the gas injector flow chart compromising the air-fuel ratio was exposed. In [52] it is reported that due to the gaseous nature of the fuel, pressure waves are present within the fueling system. In addition, it is stated that the liquid fuel in a gasoline injector acts as a damper on the injector needle as it is opening and closing, whereas a CNG injector needle will bounce when opening and closing, causing pulsations of fuel to leak through the opening [52]. It was concluded that at high engine speeds these pulses could account for up to $1 / 3$ of the total fuel injected [52].

The conditions where a combination of above-listed phenomena could occur are rapid changes in throttle position, particularly rapid cut-offs of fuel supply which follow sections with relatively high load demand. These conditions closely coincide with an exponential decrease of measured $\mathrm{CO}$ emissions, which were pinpointed as false positives. Considering the listed background on $\mathrm{N}_{2} \mathrm{O}$ formation, specifics of the TWC converters and the CNG injection systems causing $\mathrm{CH}_{4}$ leakage as well as higher amounts of $\mathrm{H}_{2} \mathrm{O}$ vapor in the exhaust gas when using $\mathrm{CNG}$, the most plausible explanation of $\mathrm{N}_{2} \mathrm{O}$ presence in the exhaust gas sample fed to the PEMS during the measuring campaign is the $\mathrm{N}_{2} \mathrm{O}$ formation in the TWC when the vehicle is using CNG. Since the false CO readings follow an exponential relation, they can be correlated to the Arrhenius equation [36] and the chemistry kinetics. To further confirm the relation to the chemistry kinetics, a short analysis of governing reactions for $\mathrm{N}_{2} \mathrm{O}$ formation is presented in Appendix B. 
Cite this paper as: Davor Rašić, Samuel Rodman Oprešnik, Tine Seljak, Rok Vihar, Urban Žvar Baškovič, Tomaž Wechtersbach, Tomaž Katrašnik, RDE-based assessment of a factory bi-fuel CNG/gasoline light-duty vehicle, Atmospheric Environment, Volume 167, 2017, Pages 523-541, ISSN 1352-2310,

https://doi.org/10.1016/j.atmosenv.2017.08.055.

\subsubsection{Supporting evidence of the hypothesis through instantaneous RDE measurements}

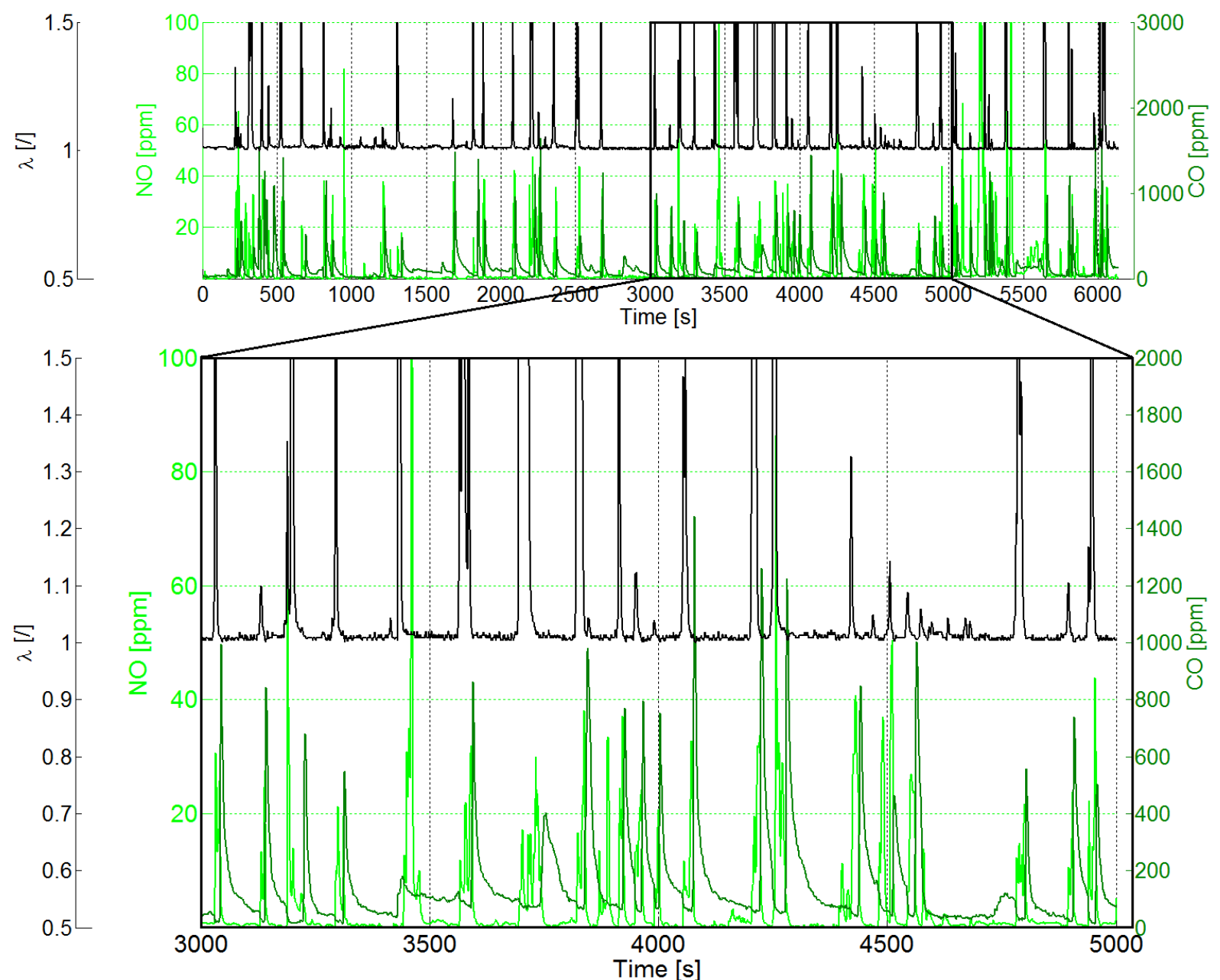

Fig. 9. Visualization of instantaneous on-road NO and CO emissions of RDE Moderate route using $\mathrm{CNG}$ 
Cite this paper as: Davor Rašić, Samuel Rodman Oprešnik, Tine Seljak, Rok Vihar, Urban Žvar Baškovič, Tomaž Wechtersbach, Tomaž Katrašnik, RDE-based assessment of a factory bi-fuel CNG/gasoline light-duty vehicle, Atmospheric Environment, Volume 167, 2017, Pages 523-541, ISSN 1352-2310,

https://doi.org/10.1016/j.atmosenv.2017.08.055.

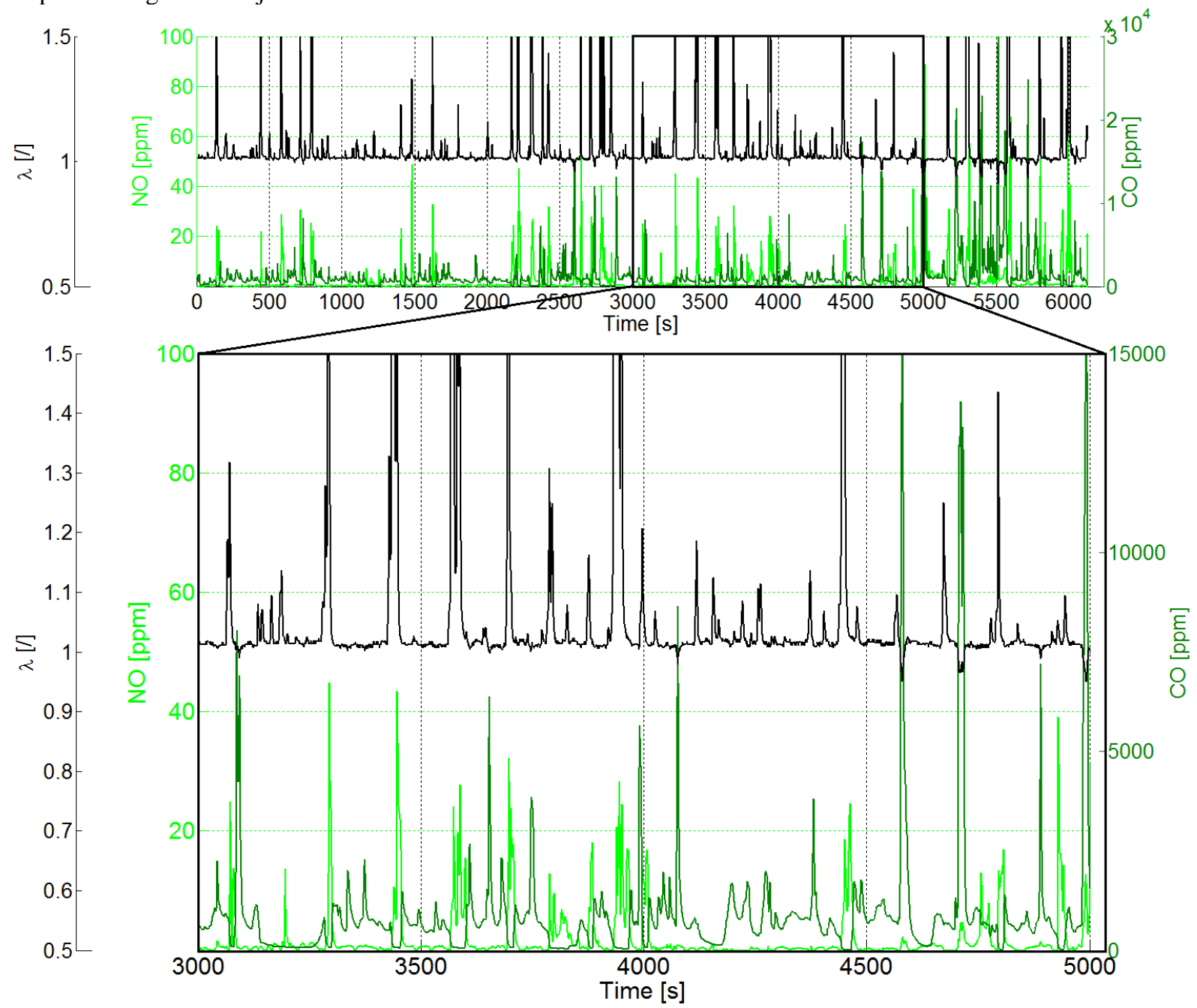

Fig. 10. Visualization of instantaneous on-road NO and CO emissions of RDE Moderate route using gasoline

Figs. 9 and 10 represent the visualization of instantaneous on-road NO and $\mathrm{CO}$ emissions of RDE Moderate when using CNG and RDE Moderate route when using gasoline, respectively. Fig. 9 clearly indicates a correlation between NO emission peaks and false CO emission peaks when using CNG on the RDE Moderate route. However, this correlation is nonexisting in Fig. 10, which represents RDE Moderate route when using gasoline.

These results can thus be considered as supporting evidence of the hypothesis introduced in the previous parts of this section. In Fig. 9 it can namely be seen that almost every NO emission peak is accompanied with a $\lambda$ peak, indicating a significant decrease in load. It is also seen in Fig. 9 that the unusual $\mathrm{CO}$ emission peaks are detected after a substantial rise of $\lambda$. It is hypothesized that the $\mathrm{CO}$ emission peak followed by an exponential decrease is, in fact, the NDIR measuring $\mathrm{N}_{2} \mathrm{O}$ generated by (B.1), (B.2) and (B.7) and yielding false $\mathrm{CO}$ reading. In sections where $\mathrm{NO}$ drops to zero, it is speculated that $\mathrm{N}_{2} \mathrm{O}$ formation ceases, hence the exponential decrease of $\mathrm{CO}$ is observed, indicating the decomposition of $\mathrm{N}_{2} \mathrm{O}$. There are several indicators, such as the correlation of the $\mathrm{CO}$ exponential falls to the Arrhenius equation [36] and to the chemistry kinetics laid down in Appendix B, proving that the $\mathrm{CO}$ false readings are not an aftermath of contamination of the analyzer with e.g. liquid water which would produce false $\mathrm{CO}$ and $\mathrm{CO}_{2}$ readings that would not follow any given chemistry relations. 
Cite this paper as: Davor Rašić, Samuel Rodman Oprešnik, Tine Seljak, Rok Vihar, Urban Žvar Baškovič, Tomaž Wechtersbach, Tomaž Katrašnik, RDE-based assessment of a factory bi-fuel CNG/gasoline light-duty vehicle, Atmospheric Environment, Volume 167, 2017, Pages 523-541, ISSN 1352-2310, https://doi.org/10.1016/j.atmosenv.2017.08.055.

\section{Conclusion}

In this paper, an RDE-based assessment of a Euro 5 factory bi-fuel CNG/gasoline light-duty vehicle equipped with the TWC was presented. The vehicle specifications were first evaluated considering the WLTP procedure followed by an appropriate selection of the WLTC cycles. Considering the RDE legislation trip boundary conditions two RDE-based routes were derived: an RDE Moderate route, satisfying the normal conditions and representing a conventional route, and an RDE Extended route, satisfying the extended conditions and representing a still plausible real-life driving route.

The test vehicle's main fuel is $\mathrm{CNG}$, therefore the engine has a higher compression ratio than a conventional spark ignition gasoline engine, which means that the gasoline mode in this bi-fuel engine does not completely mimic the behavior of a typical gasoline engine. In order to avoid knocking, the manufacturer had to optimize the ECU maps when the vehicle enters the gasoline mode. Nevertheless, the emissions of such vehicles in gasoline mode are not to be neglected, since the rarity of CNG fuelling stations and on the other hand, the frequency of gasoline pumps often forces such vehicles to run on gasoline mode. It is also important to note that the equipped TWC was designed to adequately perform on an NEDC cycle. Therefore, it was expected that some discrepancies from Euro 5 limits would be present when driving a more intensive and power-demanding route due to the breakthrough of the emissions resulting from insufficient capacity/sizing of the TWC.

The original contributions of this paper comprises of analyses of the RDE-LDV emissions of a CNG-powered vehicle, benchmarking of the CNG RDE-LDV results with the ones measured for gasoline in the same vehicle and under similar operating conditions, exposing the strong interference of $\mathrm{CO}$ and $\mathrm{N}_{2} \mathrm{O}$ infrared absorption bands, which can significantly affect the $\mathrm{CO}$ readings from the non-dispersive infrared sensor (NDIR), revealing the hypothesis why CO and $\mathrm{N}_{2} \mathrm{O}$ interference is more pronounced when using CNG in LDVs and reasoning of the time resolved on-road real driving emissions trends. For instance, the sudden load decreases and increases throughout the RDE-based routes accounted for most of the $\mathrm{NO}_{\mathrm{x}}$ emissions. The uphill driving section when using gasoline proved to emit the bulk of the cumulative THC, $\mathrm{CH}_{4}$ and $\mathrm{CO}$ emissions, whereas the downhill driving section when using $\mathrm{CNG}$ accounted for most of the THC and $\mathrm{CH}_{4}$ emissions. These effects are much more pronounced in the RDE Extended route. The in-depth analysis of the $\mathrm{CO}$ emissions when using $\mathrm{CNG}$ indicates that a significant decrease in load can be correlated with a $\mathrm{CO}$ measuring error.

This study has highlighted the difficulties of measuring $\mathrm{CO}$ emissions of bi-fuel CNG/gasoline vehicles when using CNG. CO emissions of both RDE-based routes when using $\mathrm{CNG}$ indicate that the NDIR analyzer produces a $\mathrm{CO}$ emission measurement error since this phenomenon is seen on both RDE-based routes. The detection of this phenomena was made possible by analyzing the multitude of new driving patterns, such as the downhill sections, the uphill sections, several full stops and accelerations in the urban sections, the presence of traffic, driver behavior, etc., which are significantly different to those that can be encountered in the NEDC. The measuring campaign test sequence indicates that the measurements using CNG were not conducted successively nor on the same day and that the RDE Extended route was not interleaved with the RDE Moderate route as they were conducted on separate days, therefore, the possibility of a single point in time instrument failure can be with high certainty excluded. In an attempt to additionally investigate this phenomenon, an experiment was conducted proving the influence of $\mathrm{N}_{2} \mathrm{O}$ presence in the gas fed to the PEMS on the $\mathrm{CO}$ readings of the NDIR analyzer. Experimental results indicate that even the slightest traces of $\mathrm{N}_{2} \mathrm{O}$ in the gas fed to the PEMS can lead to severe CO misreading. Specifically, the experimental results suggest that values between 100 and 600 ppm could induce such anomalous CO signals. The 
Cite this paper as: Davor Rašić, Samuel Rodman Oprešnik, Tine Seljak, Rok Vihar, Urban Žvar Baškovič, Tomaž Wechtersbach, Tomaž Katrašnik, RDE-based assessment of a factory bi-fuel CNG/gasoline light-duty vehicle, Atmospheric Environment, Volume 167, 2017, Pages 523-541, ISSN 1352-2310, https://doi.org/10.1016/j.atmosenv.2017.08.055.

suggested estimate is in line with the literature review, which suggests that $\mathrm{N}_{2} \mathrm{O}$ can be detected in catalyst-out emissions ranging from a few tens of ppm to near $800 \mathrm{ppm}$. Supporting this claim, several hypotheses of $\mathrm{N}_{2} \mathrm{O}$ formation were also presented in the paper. Furthermore, the paper also presents reasoning, based on the entire route from the mixture preparation over engine-out species composition and temperatures to chemical reactions in the TWC, why these interference issues are more significantly pronounced while using CNG. This study thus opens challenges related to $\mathrm{CO}$ emissions of NDIR analyzers that go far beyond the presented analysis. The revealed interference between $\mathrm{CO}$ and $\mathrm{N}_{2} \mathrm{O}$ measurements, causing false positives of $\mathrm{CO}$ is strongly linked to the methodology of the measurement. Devices, based on other than NDIR method for $\mathrm{CO} / \mathrm{CO}_{2}$ measurement are less sensitive to this issue, however, most of the market available PEMS are equally affected, as they strongly rely on NDIR for $\mathrm{CO} / \mathrm{CO}_{2}$. In this case, the reliability of $\mathrm{CO}$ measurement with $\mathrm{CNG}$ is similar among different manufacturers.

The highlighted time resolved on-road real driving emissions trends resulted in the cumulative emissions, which were compared against the Euro 5 regulatory limit. The indicative comparison reveals that the emissions of THC, $\mathrm{NMHC}$, and $\mathrm{NO}_{\mathrm{x}}$ of both RDE-based routes using both fuels were under the Euro 5 limits. Additionally, the $\mathrm{THC}$ and $\mathrm{NO}_{\mathrm{x}}$ emissions of both RDE-based routes using both fuels were under the type-approval limits. A comparison of the $\mathrm{NO}_{\mathrm{x}}$ emissions of both RDE-based routes using both fuels reveals that the vehicle emitted more $\mathrm{NO}_{\mathrm{x}}$ when using $\mathrm{CNG}$, which is in line with other studies and is also reasoned with the time engine parameters and time traces of the emissions. The $\mathrm{CO}_{2}$ emissions of both RDEbased routes when using both fuels were above the type-approval limits with $\mathrm{CNG}$ exceeding the type-approval limits by 6-35\% and with gasoline exceeding the type-approval limits by 66$85 \%$. The comparison of both RDE-based routes also reveals that the $\mathrm{CO}_{2}$ emissions were roughly $30 \%$ lower when using $\mathrm{CNG}$, which is in line with the literature review. Since a CO emission measurement error is detected on both RDE-based routes when using CNG, an assessment of the $\mathrm{CO}$ emissions when using $\mathrm{CNG}$ is unreliable for this fuel. The $\mathrm{CO}$ emissions of both RDE-based routes using gasoline were above the type-approval and Euro 5 limits with the CO emissions on the RDE Moderate route exceeding the type-approval limits by $920 \%$ and the Euro 5 limits by $190 \%$. The CO emissions of the RDE Extended route when using gasoline exceeded the type-approval limits by $1160 \%$ and the Euro 5 limits by $242 \%$.

\section{APPENDIX A. WLTP and RDE Legislation background and procedure}

The WLTP consists of four phases with different velocity distributions (low, medium, high and extra high). Based on the vehicle's power-to-mass ratio and its maximum velocity three different driving cycles were developed representing three different vehicle classes $[6,7]$. The length of the cycle is fixed at 1800 seconds. Gear shift points are determined mathematically and are based on the characteristics of individual vehicles [7]. In addition to the driving cycle, a procedure is also introduced to prescribe test conditions, requirements, tolerances, etc. General requirements of the vehicle state that the manufacturer shall specify the types and amounts of lubricants and coolant, as well as the tire specifications for emission testing, intended for normal vehicle operation [7]. Testing shall be performed considering several Annexes, which are in detail explained in the Global Technical Regulation no. 15 (GTR.15) [7].

Complementary to the WLTC tests, the RDE test is intended to be introduced. This test is performed in addition to the laboratory tests and is designed to check emissions outside of well-established testing procedures in laboratories. In practice, RDE implies testing of new vehicles on the road using Portable Emissions Measurement Systems (PEMS). The general 
Cite this paper as: Davor Rašić, Samuel Rodman Oprešnik, Tine Seljak, Rok Vihar, Urban Žvar Baškovič, Tomaž Wechtersbach, Tomaž Katrašnik, RDE-based assessment of a factory bi-fuel CNG/gasoline light-duty vehicle, Atmospheric Environment, Volume 167, 2017, Pages 523-541, ISSN 1352-2310, https://doi.org/10.1016/j.atmosenv.2017.08.055.

requirements and conditions of the RDE test are formulated and explained in the Appendices of Annex IIIA [8]. During the RDE test, the vehicle should not emit higher emissions than the not-to-exceed (NTE) values:

$$
N T E_{\text {pollutant }}=C F_{\text {pollutant }} \cdot E U R O 6,
$$

wherein the currently proposed $2^{\text {nd }}$ package of the RDE legislation [27] the value of $C F_{\text {pollutant }}$ (conformity factor of the pollutant) for $\mathrm{NO}_{\mathrm{x}}$ is from 09/2017 equal to 2.1 and the final value from $01 / 2020$ is $1+$ a margin of measurement uncertainties. The margin for measurement uncertainties is subjected to annual reviews and shall be revised because of the improved quality of the PEMS procedure or technical progress [27].

\section{APPENDIX B. Governing equations supporting the $\mathrm{N}_{2} \mathrm{O}$ formation in the TWC when using CNG}

Several chemical reactions are proven to produce $\mathrm{N}_{2} \mathrm{O}$ over supported rhodium, platinum and palladium catalysts [40]. The following reactions are enhanced by the presence of $\mathrm{O}_{2}$ [40]:

$$
\begin{aligned}
& 2 \mathrm{NO}+\mathrm{CO} \rightarrow \mathrm{N}_{2} \mathrm{O}+\mathrm{CO}_{2} \\
& 2 \mathrm{NO}+\mathrm{H}_{2} \rightarrow \mathrm{N}_{2} \mathrm{O}+\mathrm{H}_{2} \mathrm{O}
\end{aligned}
$$

Additional $\mathrm{H}_{2}$ and $\mathrm{CO}$ for reactions in eqns. (B.1) and (B.2) can be produced via watergas shift reaction

$$
\mathrm{CO}+\mathrm{H}_{2} \mathrm{O} \rightarrow \mathrm{CO}_{2}+\mathrm{H}_{2}
$$

and methane steam reforming:

$$
\begin{gathered}
\mathrm{CH}_{4}+\mathrm{H}_{2} \mathrm{O} \rightarrow \mathrm{CO}+3 \mathrm{H}_{2} \\
\mathrm{CH}_{4}+2 \mathrm{H}_{2} \mathrm{O} \rightarrow \mathrm{CO}_{2}+4 \mathrm{H}_{2},
\end{gathered}
$$

which are more pronounced when using $\mathrm{CNG}$ due to a higher concentration of $\mathrm{H}_{2} \mathrm{O}$ vapor compared to gasoline use. The $\mathrm{CH}_{4}$ required for (B.4) and (B.5) can be associated with the previously listed specifics of the $\mathrm{CNG}$ injection systems causing $\mathrm{CH}_{4}$ leakage.

An additional $\mathrm{N}_{2} \mathrm{O}$ production route in a TWC (B.7) has been suggested in [42]. $\mathrm{NH}_{3}$ is formed in the $200-600^{\circ} \mathrm{C}$ range via reduction of $\mathrm{NO}$ by $\mathrm{H}_{2}$ (B.6) [38], which is produced from reactions in eqns. (B.3), (B.4) and (B.5). Figs. 4, 7, B3 and B4 reveal that each Lambda increase is followed by a nonrealistic $\mathrm{CO}$ emissions peak. It can thus be hypothesized that the presence of $\mathrm{NH}_{3}$ in combination with an abundance of $\mathrm{O}_{2}$ caused by said Lambda increases could subsequently lead to $\mathrm{N}_{2} \mathrm{O}$ formation via (B.7):

$$
\begin{gathered}
2 \mathrm{NO}+5 \mathrm{H}_{2} \rightarrow 2 \mathrm{NH}_{3}+2 \mathrm{H}_{2} \mathrm{O} \\
\mathrm{NH}_{3}+2 \mathrm{O}_{2} \rightarrow \mathrm{N}_{2} \mathrm{O}+3 \mathrm{H}_{2} \mathrm{O}
\end{gathered}
$$


Cite this paper as: Davor Rašić, Samuel Rodman Oprešnik, Tine Seljak, Rok Vihar, Urban Žvar Baškovič, Tomaž Wechtersbach, Tomaž Katrašnik, RDE-based assessment of a factory bi-fuel CNG/gasoline light-duty vehicle, Atmospheric Environment, Volume 167, 2017, Pages 523-541, ISSN 1352-2310, https://doi.org/10.1016/j.atmosenv.2017.08.055.

To fully confirm the hypothesis of $\mathrm{N}_{2} \mathrm{O}$ presence in the exhaust gas having an impact on the $\mathrm{CO}$ readings of the NDIR analyzer, an experimental evaluation of the cross sensitivity of analyzers is provided in Appendix C.

\section{APPENDIX C. Cross sensitivity of $\mathrm{CO}$ and $\mathrm{N}_{2} \mathrm{O}$ in an NDIR analyzer}

The PEMS used in this measuring campaign was equipped with a non-dispersive infrared (NDIR) sensor for $\mathrm{CO}$ and $\mathrm{CO}_{2}$ measurements, which is a widely accepted method among PEMS manufacturers. NDIR gas detection method is based on the absorption of specific wavelengths of infrared radiation by different gaseous species. Ideally, species that are relevant for analysis should exhibit distinctively different footprints in the infrared spectrum resulting in minimum overlap of the absorption bands. Where overlapping is expected, the cross sensitivity is respected in calibration procedures, reducing the impact on measurement accuracy. Based on the results of this study, strong indices were identified that $\mathrm{N}_{2} \mathrm{O}$ emissions could significantly influence the PEMS measurements accuracy of $\mathrm{CO}$ emissions through this mechanism.

The interference was already confirmed in the case of FTIR analyzers [50], which use more complex methods of analysis (detailed spectral analysis instead of only band-pass analysis, typical for an NDIR analyzer). It is reported that the measurements of $\mathrm{N}_{2} \mathrm{O}$ concentrations in diluted exhaust samples and on-line real-time analyses were disrupted by interference from CO absorption bands [50]. In [41], it is reported that NDIR analyzers are even more affected by the presence of interference gasses than FTIR analyzers, primarily due to the lack of selective optic and detecting systems.

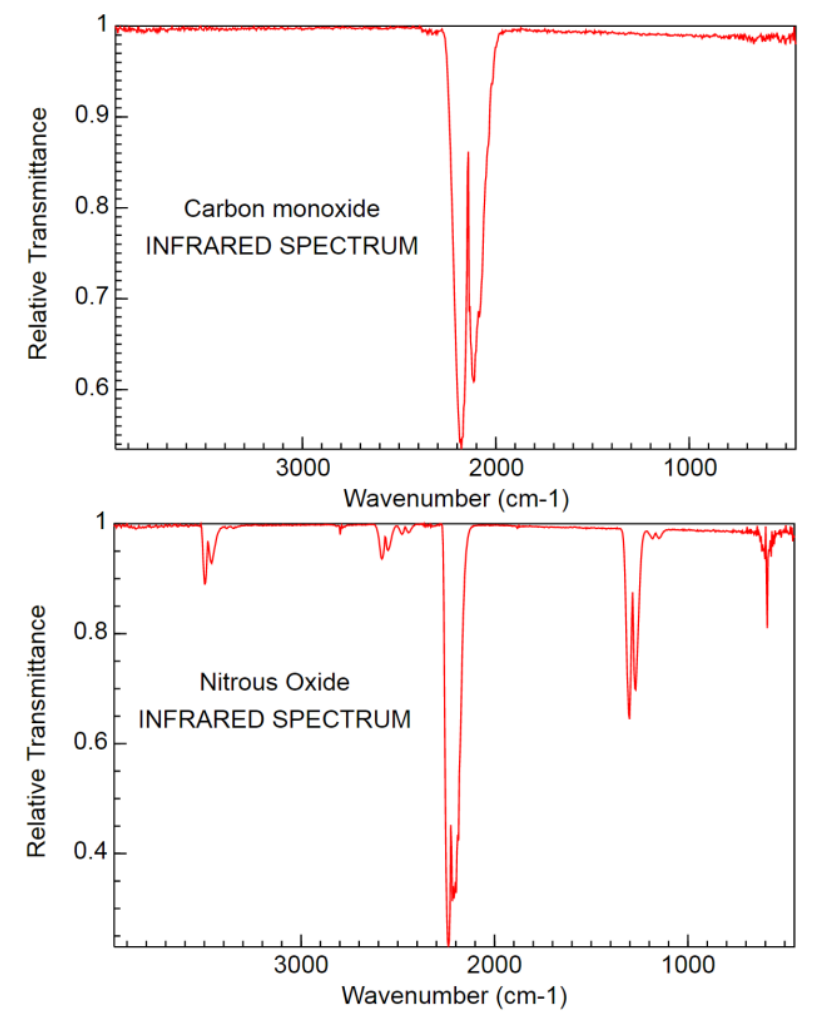

Fig. C1. Infrared spectrum of carbon monoxide $(\mathrm{CO})$ and nitrous oxide $\left(\mathrm{N}_{2} \mathrm{O}\right)$ [34] 
Cite this paper as: Davor Rašić, Samuel Rodman Oprešnik, Tine Seljak, Rok Vihar, Urban Žvar Baškovič, Tomaž Wechtersbach, Tomaž Katrašnik, RDE-based assessment of a factory bi-fuel CNG/gasoline light-duty vehicle, Atmospheric Environment, Volume 167, 2017, Pages 523-541, ISSN 1352-2310, https://doi.org/10.1016/j.atmosenv.2017.08.055.

Fig. $\mathrm{C} 1$ reveals that the infrared spectrums of $\mathrm{CO}$ and $\mathrm{N}_{2} \mathrm{O}$ are similar, especially in the interval of highest absorbance, which could induce $\mathrm{CO}$ emission measuring errors when using NDIR if the analyzed gas contains traces of $\mathrm{N}_{2} \mathrm{O}$. Therefore, in the context of this study, an experiment with a similar commercially available analyzer of another manufacturer was performed to confirm the influence of $\mathrm{N}_{2} \mathrm{O}$ presence in the gas fed to the NDIR-equipped PEMS on measured $\mathrm{CO}$ emissions as observed in on-road tests. With this objective in mind, the bag method was adopted. First, an exact volume of gas with a known composition (synthetic air and calibration gas) was fed into the binning bag. Secondly, an adequate amount of $\mathrm{N}_{2} \mathrm{O}$ was introduced into the bag to reach the desired $\mathrm{N}_{2} \mathrm{O}$ concentration. The gas from the bag was then fed to the PEMS. This procedure was repeated to obtain the following concentrations of $\mathrm{N}_{2} \mathrm{O}$ in the feed gas: 0 ppm, 100 ppm, 200 ppm, 400 ppm and $600 \mathrm{ppm}$.

Results in Fig. $\mathrm{C} 2$ illustrate the effect of $\mathrm{N}_{2} \mathrm{O}$ presence at various concentrations in the synthetic air with $0 \% \mathrm{CO}$ and in calibration gas with $0.4262 \% \mathrm{CO}$ on the outcome of CO emission measurements. It can be seen that the presence of $\mathrm{N}_{2} \mathrm{O}$ in the analyzed gas has a considerable effect on the $\mathrm{CO}$ emission measurements in an NDIR cell. The relation between $\mathrm{N}_{2} \mathrm{O}$ ppm content in the analyzed gas and measured $\mathrm{CO}$ emissions is almost linear with both carrier gasses (synthetic air and calibration) in both gas variations. These results further strengthen the hypothesis that the presence of $\mathrm{N}_{2} \mathrm{O}$ in the analyzed gas fed to the NDIRequipped PEMS causes false positives of $\mathrm{CO}$ measurements.

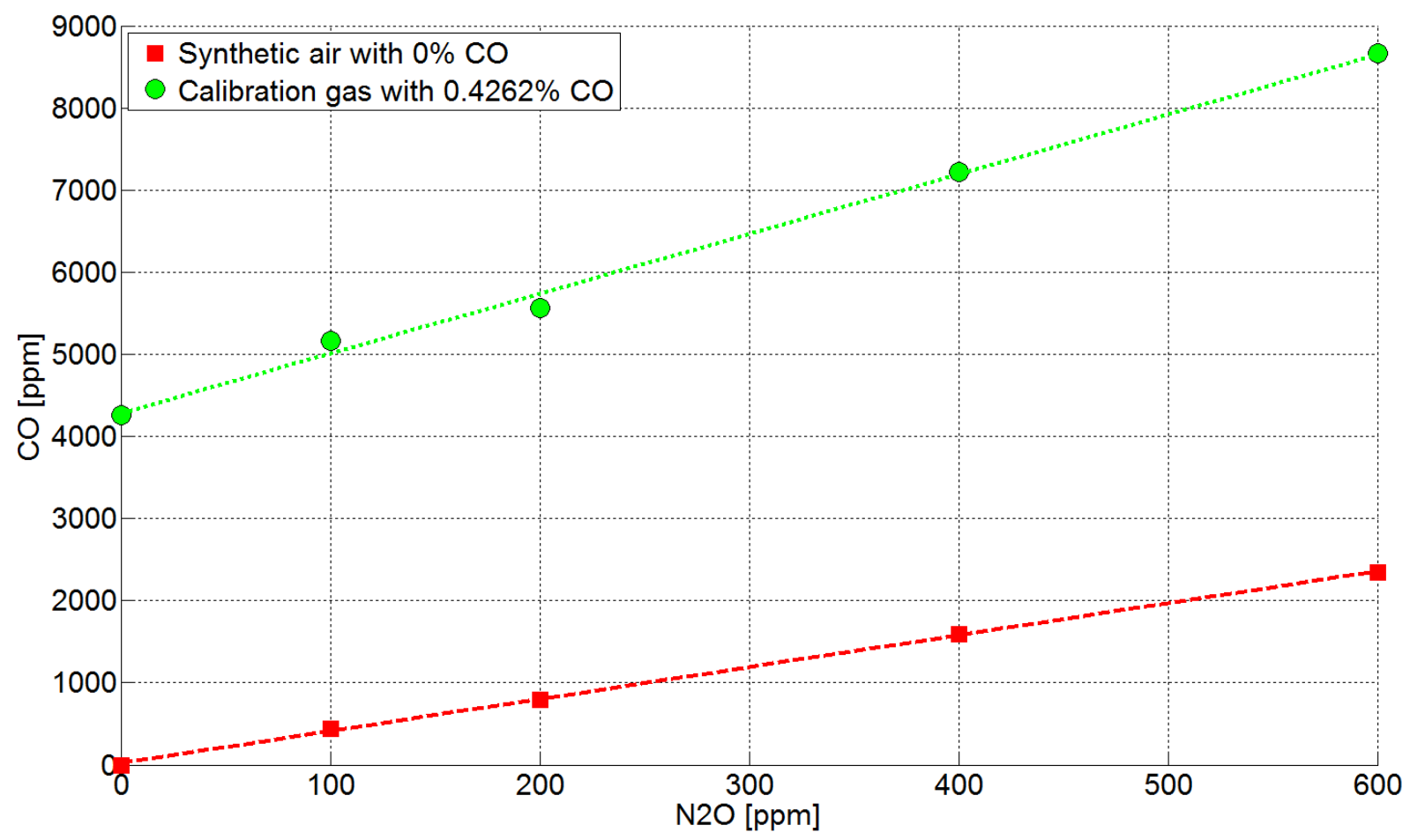

Fig. C2. Effect of $\mathrm{N}_{2} \mathrm{O}$ presence in various mixing ratios in synthetic air with $0 \% \mathrm{CO}$ (green markers) and in calibration gas with $0.4262 \%$ CO (red markers) on PEMS-measured CO emissions 
Cite this paper as: Davor Rašić, Samuel Rodman Oprešnik, Tine Seljak, Rok Vihar, Urban Žvar Baškovič, Tomaž Wechtersbach, Tomaž Katrašnik, RDE-based assessment of a factory bi-fuel CNG/gasoline light-duty vehicle, Atmospheric Environment, Volume 167, 2017, Pages 523-541, ISSN 1352-2310, https://doi.org/10.1016/j.atmosenv.2017.08.055.

\section{References}

[1] J. Andersson, J. May, C. Favre, D. Bosteels et. al.: On-Road and Chassis Dynamometer Evaluations of Emissions from Two Euro 6 Diesel Vehicles. SAE Int. J. Fuels Lubr. 7(3), 2014, pp. 919-934 doi: 10.4271/2014-01-2826.

[2] M. Weiss, P. Bonnel, J. Kühlwein, A. Provenza, U. Lambrecht, S. Alessandrini, M. Carrieroet. al. : Will Euro 6 reduce the $\mathrm{NO}_{\mathrm{X}}$ emissions of new diesel cars? - Insights from on-road tests with Portable Emissions Measurement Systems (PEMS). Atmospheric Environment, Vol. 62, December 2012, pp. 657-6

[3] J. May, D. Bosteels, C. Favre: An Assessment of Emissions from Light-Duty Vehicles using PEMS and Chassis Dynamometer Testing. SAE Int. J. Engines 7(3), 2014, pp. 1326-1335, doi: 10.4271/2014-01-1581.

[4] V. Franco, F. Posada Sanchez, J. German, P. Mock: Real-world exhaust emissions from modern diesel cars. ICCT white paper, 2014, Berlin, Germany, p.53.

[5] M. Weiss, P. Bonnel, R. Hummel, U. Manfredi, R. Colombo, G. Lanappe et. al. (2011). Analyzing on-road emissions of light-duty vehicles with Portable Emission Measurement Systems (PEMS). European Commission Joint Research Centre, Technical Report EUR 24697 EN. Publications Office of the European Union.

[6] P. Mock: Policy Update: World-Harmonized Light-Duty Vehicles Test Procedure. Washington DC, The International Council of Clean Transportation, Nov 2013

[7] United Nations Economic Commission for Europe: Proposal for a new global technical regulation on the Worldwide harmonized Light vehicles Test Procedure (WLTP). UNECE, 2014

[8] European Commission: Commission Regulation (EU) 2016/427 of 10 March 2016 amending Regulation (EC) No 692/2008 as regards emission from light passenger and commercial vehicles (Euro 6). Official Journal of the European Union, March 2016.

[9] European Commission: Commission Regulation (EC) No 692/2008 of 18 July 2008 implementing and amending Regulation (EC) No 715/2007 of the European Parliament and of the Council on type-approval of motor vehicles with respect to emissions from light passenger and commercial vehicles (Euro 5 and Euro 6) and on access to vehicle repair and maintenance information. Official Journal of the European Union, August 2008

[10] J. Czerwinski, N. Heeb, Y. Zimmerli, A. Forss, et. al.: Unregulated Emissions with TWC, Gasoline \& CNG. SAE Int. J. Engines 3(1), 2010, pp. 1099-1112, 2010, doi: 10.4271/2010-01-1286.

[11] P. Mock, J. German, A. Bandivadekar, I. Riemersma (2012): Discrepancies between type-approval and "real-world" fuel consumption and $\mathrm{CO}_{2}$ values - Assessment for 2001-2011 European passenger cars. International Council on Clean Transportation. April 2012. Retrieved from http://www.theicct.org/fuel-consumption-discrepancies 
Cite this paper as: Davor Rašić, Samuel Rodman Oprešnik, Tine Seljak, Rok Vihar, Urban Žvar Baškovič, Tomaž Wechtersbach, Tomaž Katrašnik, RDE-based assessment of a factory bi-fuel CNG/gasoline light-duty vehicle, Atmospheric Environment, Volume 167, 2017, Pages 523-541, ISSN 1352-2310, https://doi.org/10.1016/j.atmosenv.2017.08.055.

[12] P. Mock, J. Kühlwein, U. Tietge, V. Franco, A. Bandivadekar, J. German: The WLTP: How a new test procedure for cars will affect fuel consumption values in the EU. ICCT White Paper, 2014. Retrieved from: http://www.theicct.org/sites/default/files/publications/ICCT_WLTP_EffectEU_201410 29.pdf.

[13] J. Dings (2013): Mind the Gap! Why official car fuel economy figures don't match up to reality. Brussels: Transport and Environment. March 2013. Retrieved from https://www.transportenvironment.org/sites/te/files/publications/Real\%20World\%20Fu el\%20Consumption\%20v15_final.pdf

[14] P. Mock, J. German, A. Bandivadekar, I. Riemersma, N. Ligterink, N., U. Lambrecht: From laboratory to road: A 2014 Update of Official and »Real-World« Fuel Economy and $\mathrm{CO}_{2}$ Values for Passenger Cars in Europe. White Paper, The International Council on Clean Transportation, September 2015, San Francisco, USA

[15] P. Bielaczyc, J. Woodburn, S. Woodburn (2014): An assessment of regulated emissions and $\mathrm{CO}_{2}$ emissions from a European light-duty CNG-fueled vehicle in the context of Euro 6 emissions regulations. Applied Energy, 117, issue C, 2014, p. 134-141

[16] A. Marotta, J. Pavlovic, B. Ciuffo, S. Serra, G. Fontaras: Gaseous Emissions from LightDuty Vehicles: Moving from NEDC to the New WLTP Test Procedure. Environmental Science \& Technology 49 (14), 2015, 8315-8322 doi: $\underline{10.1021 / \text { acs.est.5b01364 }}$

[17] S. Rodman Oprešnik, T. Seljak, F. Bizjan, T. Katrašnik: Exhaust emissions and fuel consumption of a triple-fuel spark-ignition engine powered passenger car. Transportation Research Part D: Transport and Environment, Volume 17, Issue 3, May 2012, p 221-227

[18] J. May, D. Bosteels, C. Favre: A Comparison of Light-Duty Vehicle Emissions Over Different Test Cycles and in Real Driving Conditions. Fisita World Automotive Congress, Maastricht, June 2014

[19] D. Bosteels: Real Driving Emissions and Test Cycle Data from 4 Modern European Vehicles, IQPC International Conference on Real-Driving Emissions, Düsseldorf, September 2014

[20] A. Stewart, A. Hope-Morley, P. Mock, U. Tietge: Impact of real-world driving on emissions from UK cars and vans, The Comittee on Climate Change and Element Energy Limited, Cambridge, September 2015

[21] M. Tutuianu, P. Bonnel, B. Ciuffo, T. Haniu, N. Ichikawa, A. Marotta, J. Pavlovic, H. Steven: Development of the World-wide harmonized Light-duty Test Cycle (WLTC) and a possible pathway for its introduction in the European legislation. Transportation Research Part D: Transport and Environment, Volume 40, October 2015, p 61-75 
Cite this paper as: Davor Rašić, Samuel Rodman Oprešnik, Tine Seljak, Rok Vihar, Urban Žvar Baškovič, Tomaž Wechtersbach, Tomaž Katrašnik, RDE-based assessment of a factory bi-fuel CNG/gasoline light-duty vehicle, Atmospheric Environment, Volume 167, 2017, Pages 523-541, ISSN 1352-2310,

https://doi.org/10.1016/j.atmosenv.2017.08.055.

[22] M.I. Jahirul, H.H. Masjuki, R. Saidur, M.A. Kalam, M.H. Jayed, M.A. Wazed: Comparative engine performance and emission analysis of $\mathrm{CNG}$ and gasoline in retrofitted car engine. Applied Thermal Engineering 30 (2010), p 2219-2226

[23] K. Engeljehringer: Passenger Car Emission Regulations. AVL-Italy Tech-Day 2014, Bologna

[24] J. German: Policy Update: TIER 3 Motor Vehicle Emission and Fuel Standards. Washington DC, The International Council of Clean Transportation, Nov 2013

[25] Q. Zhang, Z. Xu, S. Shao: Combustion and emissions of a Euro VI heavy-duty natural gas using EGR and TWC. Journal of Natural Gas Science and Engineering, Volume 28, January 2016, p. 660- 671

[26] R. Gholami, M. Alyani, M., K. Smith, : Deactivation of Pd Catalysts by Water during Low Temperature Methane Oxidation Relevant to Natural Gas Vehicle Converters. Catalysts, 2015 5(2), pp.561-594. http://dx.doi.org/10.3390/catal5020561.

[27] European Commission: Commission Regulation (EU) 2016/646 of 20 April 2016 amending Regulation (EC) No 692/2008 as regards emission from light passenger and commercial vehicles (Euro 6). Official Journal of the European Union, April 2016.

[28] B. Degraeuwe, M. Weiss: Does the New European Driving Cycle (NEDC) really fail to capture the $\mathrm{NO}_{\mathrm{x}}$ emissions of diesel cars in Europe? Enviromental Pollution (2016), http://dx.doi.org/10.1016/j.envpol.2016.12.050

[29] European parliament and the Council of the European Union: Directive 2007/46/EC of the European Parliament and of the Council of 5 September 2007 establishing a framework for the approval of motor vehicles and their trailers, and of systems, components and separate technical units intended for such vehicles (Framework Directive) (Text with EEA relevance). Official Journal of the European Union L 263, 9.10.2007, p. 1-160

[30] Transport for London: In-service emissions performance of Euro 6/VI vehicles: A summary of testing using London drive cycles. London, England, September 2014. Retrieved from: http://content.tfl.gov.uk/in-service-emissions-performance-of-euro-6vivehicles.pdf

[31] M. Williams, R. Minjares: A technical summary for Euro 6/VI vehicle emission standards. International Council on Clean Transportation. June 2016. Retrieved from http://www.theicct.org/sites/default/files/publications/ICCT_Euro6-

VI_briefing_jun2016.pdf

[32] R. Muncrief: Comparison of real world off-cycle $\mathrm{NO}_{\mathrm{x}}$ emission control in Euro IV, V and VI. International Council on Clean Transportation. March 2015. Retrieved from http://www.theicct.org/sites/default/files/publications/ICCT_Briefing_EuroIV-V-VINOx_Mar2015.pdf 
Cite this paper as: Davor Rašić, Samuel Rodman Oprešnik, Tine Seljak, Rok Vihar, Urban Žvar Baškovič, Tomaž Wechtersbach, Tomaž Katrašnik, RDE-based assessment of a factory bi-fuel CNG/gasoline light-duty vehicle, Atmospheric Environment, Volume 167, 2017, Pages 523-541, ISSN 1352-2310, https://doi.org/10.1016/j.atmosenv.2017.08.055.

[33] N. De Nevers: Air Pollution Control Engineering. New York, McGraw Hill, 1995 Chapter 13, pp. 471-510

[34] S.E. Stein: IR and Mass Spectra. In NIST Chemistry WebBook; Mallard, W.G.; Linstrom, P.J., Eds. NIST Standard Reference Database Number 35; National Institute of Standards and Technology: Gaithersburg, MD, February 2000

[35] I. Nova, L. Lietti, P. Forzatti: Mechanistic aspects of the reduction of stored $\mathrm{NO}_{\mathrm{x}}$ over $\mathrm{Pt}-\mathrm{Ba} / \mathrm{Al} 2 \mathrm{O} 3$ lean $\mathrm{NO}_{\mathrm{x}}$ trap systems. Catalysis Today, Vol. 136, Issues 1-2, July 2008, p. $128-135$

[36] I. Glassman, R. Yetter: Combustion, Fourth Edition. Academic Press, New York, 2008

[37] M. Salaün, A. Kouakou, S. Da Costa: Synthetic gas bench study of a natural gas vehicle commercial catalyst in monolithic form: On the effect of gas composition. Applied Catalysis B: Environmental, Vol. 88, Issues 3-4, 20 May 2009, p 386-397

[38] I. Mejía-Centeno, S. Castillo, G. Fuentes: Enhanced emissions of $\mathrm{NH}_{3}, \mathrm{~N}_{2} \mathrm{O}$ and $\mathrm{H}_{2}$ from a Pd-only TWC and supported Pd model catalysts: Light-off and sulfur level. Applied Catalysis B: Environmental, Vol. 119-120, 30 May 2012, p. 234-240

[39] T. Huai, T. Durbin, J.W. Miller, J.M. Norbeck: Estimates of the emission rates of nitrous oxide from light-duty vehicles using different chassis dynamometer test cycles. Atmospheric Environment, Vol. 38, Issue 38, December 2004, p. 6621-6629

[40] I. Mejía-Centeno, G. Fuentes: Nitrous oxide formation during light-off over a commercial Pd-containing three-way catalytic converter: The effect of low-sulfur gasoline. Chemical Engineering Communications, 196:10, 1140-1151, doi: http://dx.doi.org/10.1080/00986440902831664

[41] S. Mosca, P. Benedetti, E. Guerriero, M. Rotatori: Assessment of nitrous oxide emission from cement plants: Real data measured with both Fourier transform infrared and nondispersive infrared techniques. Journal of the Air \& Waste Management Association, 64:11, 1270-1278, doi: http://dx.doi.org/10.1080/10962247.2014.936986

[42] T.E. Lipman, M.A. Delucchi: Emissions of Nitrous Oxide and Methane from Conventional and Alternative Fuel Motor Vehicles, Climatic Change, June 2002, Volume 53, Issue 4, p. 477-516

[43] K.H. Becker, J.C. Lörzer, R. Kurtenbach, P. Wiesen, T.E., Jensen, T.J. Wallington: Contribution of vehicle exhaust to the global $\mathrm{N}_{2} \mathrm{O}$ budget. Chemosphere - Global Change Science, Vol. 2, Issues 3-4, 1 July 2000, p. 387-395

[44] J.L. Jimenez, J.B. McManus, J.H. Shorter, D.D. Nelson, M.S. Zahniser, M. Koplow, G.J. McRae, C.E. Kolb: Cross road and mobile tunable infrared laser measurements of nitrous oxide emissions from motor vehicles. Chemosphere - Global Change Science, Vol. 2, Issues 3-4, 1 July 2000, p. 397-412 
Cite this paper as: Davor Rašić, Samuel Rodman Oprešnik, Tine Seljak, Rok Vihar, Urban Žvar Baškovič, Tomaž Wechtersbach, Tomaž Katrašnik, RDE-based assessment of a factory bi-fuel CNG/gasoline light-duty vehicle, Atmospheric Environment, Volume 167, 2017, Pages 523-541, ISSN 1352-2310, https://doi.org/10.1016/j.atmosenv.2017.08.055.

[45] M. Odaka, N. Koike, H. Suzuki: Influence of catalyst deactivation on N2O emissions from automobiles. Chemosphere - Global Change Science, Vol. 2, Issues 3-4, 1 July 2000, p. 413-423

[46] M. Baratta, H. Kheshtinejad, D. Laurenzano, D. Misul, B. Brunetti: Modelling aspects of a CNG injection system to predict its behavior under steady state conditions and throughout driving cycle. Journal of Natural Gas Science and Engineering, Vol. 24, May 2015, p. 52-63

[47] R. Suarez-Bertoa, A.A. Zardini, C. Astorga: Ammonia exhaust emissions from spark ignition vehicles over the New European Driving Cycle. Atmospheric Environment, Vol. 97, November 2014, p. 43-53

[48] R. Suarez-Bertoa, A.A. Zardini, V. Lilova, et. al.: Intercomparison of real-time tailpipe ammonia measurements from vehicles tested over the new world-harmonized light-duty vehicle test cycle (WLTC). Environ Sci Pollut Res (2015) 22: 7450. doi: $10.1007 / \mathrm{s} 11356-015-4267-3$

[49] H. Ohtsuka: Pt-Rh/CeO2-A12O3 for Controlling Emissions from Natural Gas Engines: Three-Way Catalytic Activity at Low Temperatures and Effects of SO2 Aging. Emission Control Science and Technology, 2015, 1(1), p. 108-116

[50] A.M. Winer, E. Behrentz, Estimates of nitrous oxide emissions from motor vehicles and the effect of catalyst composition and aging. Final Report. State of California Air Resources Board. Contract No. 02-313 (2005).

[51] E. Pipitone, S. Beccari, M. Cammalleri, G. Genchi: Experimental Model-Based Linearization of a S.I. Engine Gas Injector Flow Chart. Strojniški vestnik - Journal of Mechanical Engineering 60(2014)11, 694-708, doi: 10.5545/sv-jme.2013.1321

[52] M. Chiodi, H. Berner, M. Bargende: Investigation on different Injection Strategies in a Direct-Injected Turbocharged CNG-Engine. SAE Technical Paper 2006-01-3000, 2006, doi: 10.4271/2006-01-3000.

[53] L. Kubiak, R. Matarrese, L. Castoldi, L. Lietti, M. Daturi, P. Forzatti: Study of $\mathrm{N}_{2} \mathrm{O}$ Formation over Rh- and Pt-Based LNT Catalysts. Catalysts 2016, 6, 36.

[54] P. Mock: Results of the German transport ministry's post-VW vehicle testing. The International Council on Clean Transportation, $25^{\text {th }}$ of April 2016, San Francisco, USA 